\title{
Genetic and Biochemical Analysis of cis Regulatory Elements within the Keratinocyte Enhancer Region of the Human Papillomavirus Type 31 Upstream Regulatory Region during Different Stages of the Viral Life Cycle
}

\author{
Ellora Sen, Samina Alam, and Craig Meyers* \\ Department of Microbiology and Immunology, The Pennsylvania State University College of Medicine, Hershey, \\ Pennsylvania 17033
}

Received 27 June 2003/Accepted 29 September 2003

\begin{abstract}
Using linker scanning mutational analysis, we recently identified potential cis regulatory elements contained within the $5^{\prime}$ upstream regulatory region (URR) domain and auxiliary enhancer (AE) region of the human papillomavirus type 31 (HPV31) URR involved in the regulation of E6/E7 promoter activity at different stages of the viral life cycle. For the present study, we extended the linker scanning mutational analysis to identify potential cis elements located in the keratinocyte enhancer (KE) region (nucleotides 7511 to 7762) of the HPV31 URR and to characterize cellular factors that bind to these elements under conditions representing different stages of the viral life cycle. The linker scanning mutational analysis identified viral cis elements located in the KE region that regulate transcription in the presence and absence of any viral gene products or viral DNA replication and determine the role of host tissue differentiation on viral transcriptional regulation. Using electrophoretic mobility shift assays, we illustrated defined reorganization in the composition of cellular transcription factors binding to the same cis regulatory elements at different stages of the HPV differentiationdependent life cycle. Our studies provide an extensive map of functional elements in the KE region of the HPV31 URR, identify cis regulatory elements that exhibit significant transcription regulatory potential, and illustrate changes in specific protein-DNA interactions at different stages of the viral life cycle. The variable recruitment of transcription factors to the same cis element under different cellular conditions may represent a mechanism underlying the tight link between keratinocyte differentiation and E6/E7 expression.
\end{abstract}

Human papillomaviruses (HPVs) are small DNA viruses that have a tropism for epithelial tissues and are capable of inducing benign and malignant lesions (28). HPV types associated with an increased risk of cervical malignancy are known as the high-risk HPVs and include HPV types 16, 18, 31, 33, and $45(13,22,54)$. The oncogenic potential of the high-risk viruses can be attributed to the E6 and E7 genes, which encode oncoproteins that interact with the cell cycle regulatory proteins p53 and retinoblastoma, respectively $(25,60)$. The life cycle of HPV is tightly linked to the differentiation state of its natural host tissue, the squamous epithelium (46). HPV transcription is regulated in a complex manner according to the differentiation state of the host $(1,52,62)$ and the stage of the viral life cycle (62). The E6/E7 promoter (known as p99 for HPV31) is regulated by cis-acting elements located in the upstream regulatory region (URR) of the viral genome $(30,34$, $40,51,62)$. The concerted interaction and dynamic balance of the regulatory activities exhibited by these cis regulatory elements give rise to a number of hallmarks of the HPV life cycle, including keratinocyte host cell specificity and a tight link between host tissue differentiation and the viral life cycle.

The URR of HPV31 can be divided into several functional domains as follows: a 5' URR domain, an auxiliary enhancer

\footnotetext{
* Corresponding author. Mailing address: Department of Microbiology and Immunology, The Pennsylvania State University College of Medicine, Hershey, PA 17033. Phone (717) 531-6240. Fax: (717) 5314600. E-mail: cmm10@psu.edu.
}

(AE) domain, an epithelial cell-specific keratinocyte enhancer (KE) domain, the minimal origin, and the $\mathrm{p} 99$ promoter from which the early transcripts originate (30). Using linker scanning mutational analysis, we recently identified cis regulatory elements contained within a portion of the $5^{\prime}$ URR and in the $\mathrm{AE}$ domain that control gene expression from the E6/E7 promoter at different stages of the viral life cycle (62). For HPV31, the KE (nucleotides [nt] 7495 to 7789 ) is regarded as the major transcriptional regulator of E6/E7 expression $(30,40)$. By sequentially replacing 18 -bp sequences with a polylinker to generate 14 linker scanning mutants, we extended our linker scanning mutational analysis to systematically identify cis elements located within a major portion of the KE region (nt 7511 to 7762) that are involved in transcriptional regulation of $\mathrm{p} 99$ promoter activity at different stages of the viral life cycle.

The activity of the E6/E7 promoter is regulated by a complex interplay of cellular and viral factors that bind to the URR. A number of cellular transcription factors, including AP-1 family members, AP-2, CDP, C/EBP, GRE, KRF-1, Oct-1, Sp1, Sp3, TEF-1, and YY1, have been reported to contribute either positively or negatively to the regulation of HPV E6/E7 gene expression $(8-10,26,27,32,33,42,50,68,77)$. The viral E2 protein is a major regulator of transcriptional control and has been shown by others to primarily function as a repressor of E6 and E7 expression $(12,16,19,55)$. Studies have shown that the transcriptional activity of the minimal functional enhancer region (nt 7511 to 7772), located within the KE region of HPV31, is regulated through a synergistic interaction of AP-1 with 
TABLE 1. Oligonucleotide primers used for the construction of linker scanning mutants $\mathrm{C} 1$ to $\mathrm{C} 14$

\begin{tabular}{|c|c|c|c|c|c|c|c|c|c|c|c|c|c|c|c|c|c|c|c|c|c|}
\hline \multirow{3}{*}{$\begin{array}{l}\begin{array}{c}\text { Primer } \\
\text { set }^{a}\end{array} \\
\mathrm{C} 1\end{array}$} & \multicolumn{21}{|c|}{ Sequence $\left(5^{\prime} \rightarrow 3^{\prime}\right)$} \\
\hline & \multicolumn{11}{|c|}{ Primer 1} & \multicolumn{10}{|c|}{ Primer 2} \\
\hline & CGC & GGG & $\mathrm{CCC}$ & $\mathrm{CAT}$ & ATG & TAC & TAG & CAT & GTT & TAA & AC & CGC & GGG & $\mathrm{CCC}$ & TGA & $\mathrm{TCA}$ & $\mathrm{AGT}$ & TCT & GCG & GTT & TTT GG \\
\hline $\mathrm{C} 2$ & CGC & GGG & $\mathrm{CCC}$ & $\mathrm{CAT}$ & ATG & $\mathrm{ACT}$ & $\mathrm{GCA}$ & TCA & GCA & TAG & $\mathrm{TT}$ & CGC & GGG & $\mathrm{CCC}$ & TGA & $\mathrm{TCA}$ & TTC & CTG & $\mathrm{AAT}$ & ACT & AGT TT \\
\hline $\mathrm{C} 3$ & CGC & GGG & $\mathrm{CCC}$ & $\mathrm{CAT}$ & ATG & ACC & AAA & AAC & CGC & AGA & AC & CGC & GGG & $\mathrm{CCC}$ & TGA & $\mathrm{TCA}$ & TGC & CAA & $\mathrm{CAT}$ & TCT & GGC TT \\
\hline $\mathrm{C} 4$ & CGC & GGG & $\mathrm{CCC}$ & $\mathrm{CAT}$ & ATG & $\mathrm{AAA}$ & $\mathrm{ACT}$ & AGT & ATT & CAG & GA & CGC & GGG & $\mathrm{CCC}$ & TGA & TCA & TAG & TTT & $\mathrm{CCT}$ & GCC & TAA CA \\
\hline C5 & CGC & GGG & $\mathrm{CCC}$ & $\mathrm{CAT}$ & ATG & CAA & GCC & AGA & ATG & TTG & GC & CGC & GGG & $\mathrm{CCC}$ & TGA & $\mathrm{TCA}$ & $\mathrm{ACC}$ & TTG & $\mathrm{CCA}$ & $\mathrm{ACA}$ & TAT AA \\
\hline C6 & CGC & GGG & $\mathrm{CCC}$ & $\mathrm{CAT}$ & ATG & GTG & TTA & GGC & AGG & $\mathrm{AAA}$ & CT & CGC & GGG & $\mathrm{CCC}$ & TGA & TCA & $\mathrm{CCA}$ & GTC & CAA & СтT & TGC AA \\
\hline C7 & CGC & GGG & $\mathrm{CCC}$ & $\mathrm{CAT}$ & ATG & ATT & ATA & TGT & TGG & CAA & GG & CGC & GGG & $\mathrm{CCC}$ & TGA & TCA & TAT & $\mathrm{ACT}$ & ATG & AAT & CAT GT \\
\hline C8 & CGC & GGG & $\mathrm{CCC}$ & $\mathrm{CAT}$ & ATG & ATT & $\mathrm{GCA}$ & AAG & TTG & GAC & TG & CGC & GGG & $\mathrm{CCC}$ & TGA & $\mathrm{TCA}$ & TGT & TTA & $\mathrm{AAT}$ & $\mathrm{ACA}$ & ACT GT \\
\hline C9 & CGC & GGG & $\mathrm{CCC}$ & CAT & ATG & AAC & ATG & ATT & CAT & AGT & $\mathrm{AT}$ & CGC & GGG & $\mathrm{CCC}$ & TGA & TCA & GTT & CAA & CTA & TGT & GTC AT \\
\hline $\mathrm{C} 10$ & CGC & GGG & $\mathrm{CCC}$ & $\mathrm{CAT}$ & ATG & TAC & AGT & TGT & ATT & TAA & $\mathrm{AC}$ & CGC & GGG & $\mathrm{CCC}$ & TGA & $\mathrm{TCA}$ & $\mathrm{CAC}$ & ATA & TAT & TAT & ATT AT \\
\hline C11 & CGC & GGG & $\mathrm{CCC}$ & $\mathrm{CAT}$ & ATG & CAT & GAC & $\mathrm{ACA}$ & TAG & TTG & $\mathrm{AA}$ & CGC & GGG & $\mathrm{CCC}$ & TGA & $\mathrm{TCA}$ & CTA & CAC & $\mathrm{ACC}$ & TTA & AAC $T G$ \\
\hline C12 & CGC & GGG & $\mathrm{CCC}$ & $\mathrm{CAT}$ & ATG & GAT & $\mathrm{AAT}$ & ATA & ATA & TAT & GT & CGC & GGG & $\mathrm{CCC}$ & TGA & TCA & $\mathrm{TTT}$ & TAG & GCA & CAT & ATT TT \\
\hline C13 & CGC & GGG & $\mathrm{CCC}$ & CAT & ATG & $\mathrm{GCA}$ & GTT & TAA & GGT & GTG & TA & CGC & GGG & $\mathrm{CCC}$ & TGA & TCA & TAG & ATT & ATC & TAT & ATC CT \\
\hline C14 & CGC & GGG & $\mathrm{CCC}$ & $\mathrm{CAT}$ & ATG & CAA & AAT & ATG & TGC & CTA & $\mathrm{AA}$ & CGC & GGG & $\mathrm{CCC}$ & TGA & $\mathrm{TCA}$ & GAT & TGC & AGT & GCT & GGC TT \\
\hline External & CGC & GGT & ACC & CGG & GGA & TCC & TCT & AGA & GTC & GAC & $(\alpha)$ & CGC & AAG & $\mathrm{CTT}$ & GCC & TGC & AGA & TTT & TTG & AAC & $\operatorname{AT} \quad(\beta)$ \\
\hline
\end{tabular}

${ }^{a}$ The external and internal primers used for the construction of the $5^{\prime}$ and $3^{\prime}$ halves of each mutant are shown in columns 1 and 2 , respectively.

novel factors NF-1-like and KRF-1, and variations in the constituents of the AP-1 complex that bind to the minimal enhancer are observed for different cell types (40). The expression profiles of several cellular transcription factors that interact with the HPV URR have the potential to change during keratinocyte differentiation $(1,2,5,53,71,76)$. In view of the findings that changes in the distribution pattern of transcription factors play a role in determining the tropism of HPV (40), the combinatorial effect of positive or negative regulators interacting with a given cis element in the HPV URR at different stages of the viral life cycle could provide an additional level of regulation of E6/E7 expression. Our mutational analysis illustrates the differences in the transcriptional utilization of specific regions of the KE region, depending on the state of the viral life cycle. We performed electrophoretic mobility shift assays (EMSAs) to investigate the binding specificity of the cis regulatory elements located in the KE region to cellular factors during different stages of the viral life cycle. Our results demonstrate changes in the constituents of cellular transcription factors that bind to the individual cis regulatory elements during the viral life cycle.

\section{MATERIALS AND METHODS}

Plasmids and oligonucleotides. A 1,112-bp sequence (nt 6921 to 121) encompassing the complete URR of HPV31 was amplified by PCR and cloned into the pGL2 basic vector as described previously (62). Using this wild-type URR construct, 18-bp linker scanning mutations were introduced across nt 7511 to 7762 by previously described methods (62). For the generation of mutants spanning the URR, internal primers specific to each mutant and two external primers, $\alpha$ and $\beta$, common to all mutants were synthesized. The oligonucleotide primers used in the construction of the linker scanning mutants are shown in Table 1. With the external and matched internal primers, 14 linker scanning mutants spanning nt 7511 to 7762 of the URR were generated by replacing $18 \mathrm{bp}$ of the wild-type sequence with an $N d e \mathrm{I}-A p a \mathrm{I}-B c l \mathrm{I}$ polylinker, as described previously (62). The mutants were designated $\mathrm{C} 1$ to $\mathrm{C} 14$.

Cell culture. C33A, an HPV-negative cell line derived from a cervical carcinoma, was cultured in Dulbecco's modified Eagle's medium containing $10 \%$ fetal bovine serum and gentamicin. The CIN-612 9E cell line was established from a cervical intraepithelial neoplasia grade I (CIN-I) biopsy and contains HPV31b DNA (11). In the CIN-612 clonal derivative 9E (9E), the HPV31b genome is maintained episomally at 50 to 100 copy numbers per cell (31). 9E cells were grown in E medium containing 5\% fetal bovine serum in the presence of mitomycin C-treated J2 3 T3 feeder cells, as previously described (46). Normal human epidermal keratinocytes (NHEK) were maintained as monolayer cultures without feeder cells in serum-free 154 medium supplemented with the Human Keratinocyte Growth supplement kit (Cascade Biologics Inc., Portland, Oreg.).

Transfection and luciferase assay. Transfection experiments were performed with each of the above cell lines by use of PerFect Lipids (Pfx-8) (Invitrogen, Carlsbad, Calif.) as described previously (62). Following transfection, the cells were allowed to grow either as undifferentiated monolayer cultures or suspended in methylcellulose to differentiate. After $48 \mathrm{~h}$, cell extracts were prepared with passive lysis buffer (Promega, Madison, Wis.) and luciferase activity was assayed by use of the Luciferase Assay system (Promega) according to the manufacturer's instructions. The effect of each URR linker scanning mutant was determined by comparing the luciferase activity of the mutant construct with that of the wildtype URR construct and was expressed as the fold change compared to the wild-type URR, which was set to 1.0.

Nuclear extract preparation and EMSAs. Nuclear extracts from CIN-612 9E cells were prepared as described previously (61). Briefly, $2 \times 10^{6}$ cells were suspended in $400 \mu \mathrm{l}$ of buffer A (10 mM HEPES [pH 7.9], $10 \mathrm{mM} \mathrm{KCl}, 0.1 \mathrm{mM}$ EDTA, $0.1 \mathrm{mM}$ EGTA, $1 \mathrm{mM}$ dithiothreitol [DTT], and $0.5 \mathrm{mM}$ phenylmethylsulfonyl fluoride [PMSF]). The cells were allowed to swell on ice for $20 \mathrm{~min}$, after which $25 \mu$ l of IGEPAL CA-630 (Sigma, St. Louis, Mo.) was added, followed by vigorous mixing for $20 \mathrm{~s}$. After centrifugation for $30 \mathrm{~s}$, the pellet was recovered and resuspended in buffer B (20 mM HEPES [pH 7.9], $400 \mathrm{mM} \mathrm{KCl,}$ $1 \mathrm{mM}$ EDTA, and $0.5 \mathrm{mM}$ PMSF), shaken for $30 \mathrm{~min}$ at $4^{\circ} \mathrm{C}$, and centrifuged for $5 \mathrm{~min}$ at $4^{\circ} \mathrm{C}$. The supernatants were recovered, and the protein concentration was measured by use of the BCA protein assay kit (Pierce, Rockford, Ill.). Blunt-ended double-stranded oligonucleotides (Table 2) were labeled with $\left[{ }^{32} \mathrm{P}\right]$ ATP and T4 polynucleotide kinase as previously described (15). Competition EMSA was performed by incubating nuclear extracts $(10 \mu \mathrm{g})$ with poly $(\mathrm{dI}-$ dC) $(2 \mu \mathrm{g})$ (Pharmacia) in the presence or absence of a 100 -fold excess of unlabeled homologous or heterologous oligonucleotide for $20 \mathrm{~min}$ in a $20-\mu \mathrm{l}$ reaction volume containing $5 \%$ glycerol, $150 \mathrm{mM} \mathrm{KCl,} 0.5 \mathrm{mM}$ EDTA, and 0.5 $\mathrm{mM}$ DTT. After incubation, $0.75 \mathrm{ng}$ of ${ }^{32} \mathrm{P}$-labeled oligonucleotide probe was added and the reaction was incubated at room temperature for an additional 30 min. For monitoring of cellular protein composition in gel mobility shift assays, $2 \mu \mathrm{g}$ of polyclonal antibodies directed against NF-1, Oct-1, and the Jun/Fos and $\mathrm{C} / \mathrm{EBP}$ family members was added, and the reactions were further incubated at room temperature for $30 \mathrm{~min}$. The DNA-protein complexes were then separated from free probe by electrophoresis on a $6 \%$ Tris-glycine-EDTA gel at $200 \mathrm{~V}$ and $4^{\circ} \mathrm{C}$. All antibodies were purchased from Santa Cruz Biotechnology (Santa Cruz, Calif.). The following antibodies were used: $\mathrm{C} / \mathrm{EBP} \alpha$ (sc-61X), C/EBP $\beta$ (sc150X), NF-1 (sc-870X), Oct-1 (sc-21X), c-Fos (sc-52X), JunB (sc-46X), c-Jun (sc-45X), and JunD (sc-74X).

Western blot analysis. Total protein from the nuclear extract for use in Western blotting was prepared as described previously (45), with the following modifications. Two hundred fifty microliters of nuclear extract was added to an equal volume of buffer (50 $\mathrm{mM} \mathrm{NaPO}_{4}$ [pH 7.2], $5 \mathrm{mM}$ EDTA, $50 \mathrm{mM} \mathrm{NaF}, 0.5 \mu \mathrm{g}$ of leupeptin per $\mathrm{ml}, 0.5 \mu \mathrm{g}$ of pepstatin per $\mathrm{ml}, 20 \mu \mathrm{g}$ of aprotinin per $\mathrm{ml}, 0.2 \mathrm{mM}$ sodium vanadate $\left[\mathrm{Na}_{3} \mathrm{VO}_{4}\right], 1 \mathrm{mM}$ DTT, $1 \mathrm{mM} \mathrm{PMSF}$, and $2 \%$ [wt/vol] sodium 
TABLE 2. Oligonucleotides used for $\mathrm{EMSA}^{a}$

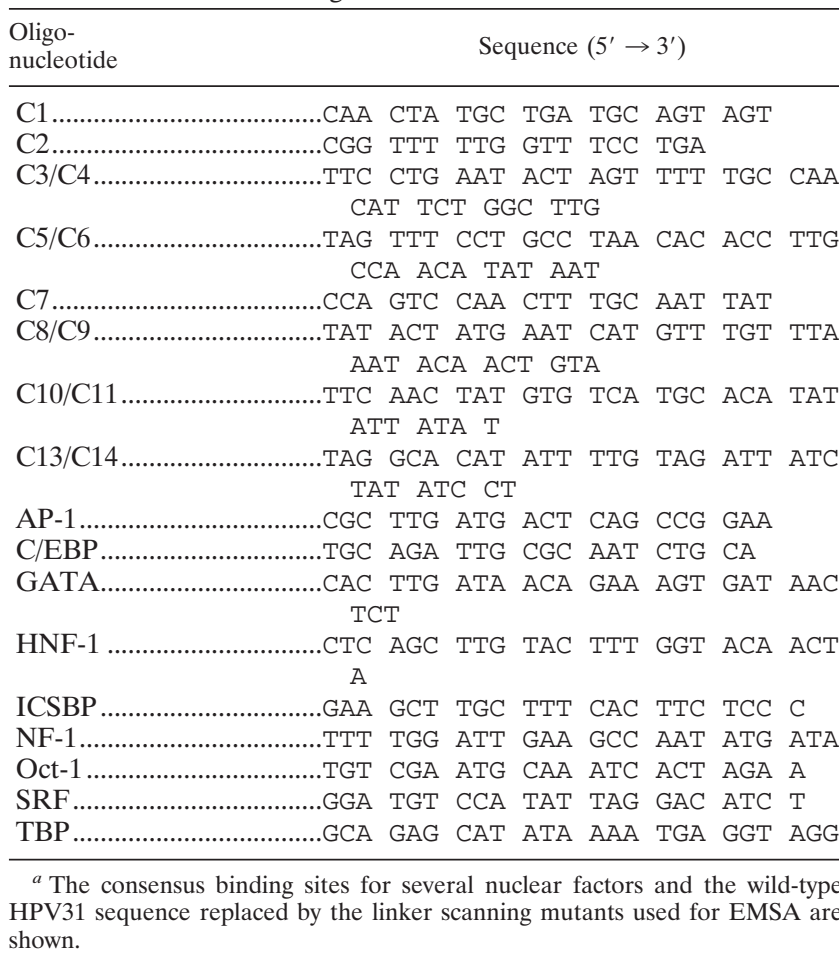

dodecyl sulfate [SDS]). The samples were boiled in a water bath for $8 \mathrm{~min}$, with mixing on a vortex machine at 1-min intervals, followed by the addition of $250 \mu \mathrm{l}$ of $5 \times$ sample loading dye (final concentrations, $100 \mathrm{mM}$ Tris [pH 8.0], $5 \mathrm{mM}$ EDTA, $10 \%$ [wt $/ \mathrm{vol}$ ] sucrose, $2 \%$ [wt $/ \mathrm{vol}]$ SDS, $33 \mathrm{mM} \mathrm{DTT}$, and $0.1 \mathrm{mg}$ of Pyronin Y per $\mathrm{ml}$ ). Protein concentrations were determined by use of the Peterson protein assay as previously described (45). Fifteen micrograms of total protein was resolved onto an SDS-7.5\% polyacrylamide gel. Proteins were transferred to a nitrocellulose membrane, and the membrane was incubated with polyclonal antibodies (1:20,000 dilution) against NF-1, C/EBP $\alpha, C / E B P \beta, c-F o s$, c-Jun, JunB, JunD, and Oct-1. The same antibodies as those used in the gel shift assay were used for Western blot analysis. After being washed, blots were incubated with anti-rabbit horseradish peroxidase-linked secondary antibody (Amersham Life Science) per the manufacturer's instructions. The proteins were detected by use of a chemiluminescence reagent (Perkin-Elmer Life Science, Boston, Mass.) as previously described (45).

\section{RESULTS}

Linker scanning mutants. We constructed a series of linker scanning mutants to investigate the role of cis regulatory elements contained within the KE region of HPV31 URR in regulating viral early gene expression. We utilized linker substitution mutational analysis for mapping cis elements in order to maintain spatial positioning of the various cis elements involved in transcription with respect to the promoter. Consecutive 18-bp linker substitution mutations were engineered across a 252-bp stretch of the HPV31 URR (nt 7511 to 7762), corresponding to most of the $\mathrm{KE}$ region, as described in Materials and Methods. A map of the HPV31 URR, indicating the region that was replaced by polylinkers, is shown in Fig. 1. For convenience in nomenclature, the entire URR has been divided into four regions, named A, B, C, and D, each of which consists of $252 \mathrm{bp}$ (62). The region of interest for this study is the $\mathrm{C}$ region, and the relative positions of the linker scanning mutants $\mathrm{C} 1$ to $\mathrm{C} 14$ are shown in Fig. 1A.
KE region cis sequences modulating $\mathbf{p 9 9}$ promoter activity in undifferentiated cells. cis sequences involved in viral transcriptional control have the potential to influence transcription at several levels. These include the ability to modify HPV transcription during the earliest state of the viral life cycle, which is immediately following infection, when there is minimal viral replication and viral gene product expression. Because monolayer keratinocyte cultures mimic the basal cell environment seen by the virus immediately upon infection, we first analyzed the effect of the URR mutants in monolayer culture.

In order to identify the cis regulatory sequences in the $\mathrm{KE}$ region that regulate the $\mathrm{p} 99$ promoter immediately upon infection, we carried out transfection of the wild type and mutant constructs $\mathrm{C} 1$ to $\mathrm{C} 14$ in undifferentiated monolayer cell culture. C33A, an HPV-negative cell line derived from a cervical carcinoma, has been commonly used by numerous investigators to analyze HPV transcriptional activity. Transfection with linker scanning mutants $\mathrm{C} 8$ and $\mathrm{C} 14$ decreased promoter activity by $90 \%$, whereas transcriptional activity from the p99 promoter decreased by 70 to $80 \%$ when C33A cells were transfected with mutants $\mathrm{C} 4, \mathrm{C} 7, \mathrm{C} 10, \mathrm{C} 11$, and $\mathrm{C} 13$, suggesting that all of these regions are required for normal p99 promoter activity (Fig. 2A). Transfection with $\mathrm{C} 3$ and $\mathrm{C} 12$ mutants caused an approximately $50 \%$ decrease in promoter activity. On the other hand, transfection with mutant C5 resulted in an approximately $50 \%$ increase in activity compared to the wild type (Fig. 2A).

The CIN-612 9E cell line maintains the HPV31b genome episomally at about 50 copies per cell and is capable of virus production upon differentiation in organotypic raft culture (47). As such, 9E cells support normal viral gene expression. Monolayer cultures of 9E cells (representing undifferentiated basal cells) were transfected with linker scanning mutants $\mathrm{C} 1$ to $\mathrm{C} 14$ to discern the effect of viral cis elements on transcriptional regulation in the presence of viral gene products. As seen with C33A cells, mutants C3, C7, C8, C10, C12, C13, and $\mathrm{C} 14$ resulted in a significant decrease in activity following transfection into 9E cells (Fig. 2A). However, unlike C33A, p99 promoter activity was not enhanced upon transfection of 9E cells with mutant C5. In contrast to what was seen with C33A cells, in which transfection with mutant $\mathrm{C} 2$ had no effect on transcriptional activity compared to the wild-type construct, an approximately $70 \%$ decrease in promoter activity was observed when 9E cells were transfected with the same mutant. On the other hand, while transfection of 9E cells with mutant $\mathrm{C} 4$ had no effect on promoter activity, a $70 \%$ decrease in activity was observed when C33A cells were transfected with this mutant. Therefore, regulation of $\mathrm{p} 99$ promoter activity by cis elements located in the region replaced by mutants $\mathrm{C} 2$ and $\mathrm{C} 4$ is cell type specific and may be affected by the presence of viral gene products.

Analysis of transcriptional regulation by viral cis elements was also performed in NHEK, as they represent the initial target for HPV infection. A generalized repression in promoter activity was observed upon transfection of NHEK with mutants $\mathrm{C} 1$ through $\mathrm{C} 14$. We have previously observed a similar repression of p99 activity upon transfection of NHEK with mutants B1 to B14 (nt 7259 to 7510) (62). Transfection of NHEK with mutants $\mathrm{C} 8, \mathrm{C} 10, \mathrm{C} 13$, and $\mathrm{C} 14$ resulted in an 
$\mathbf{A}$
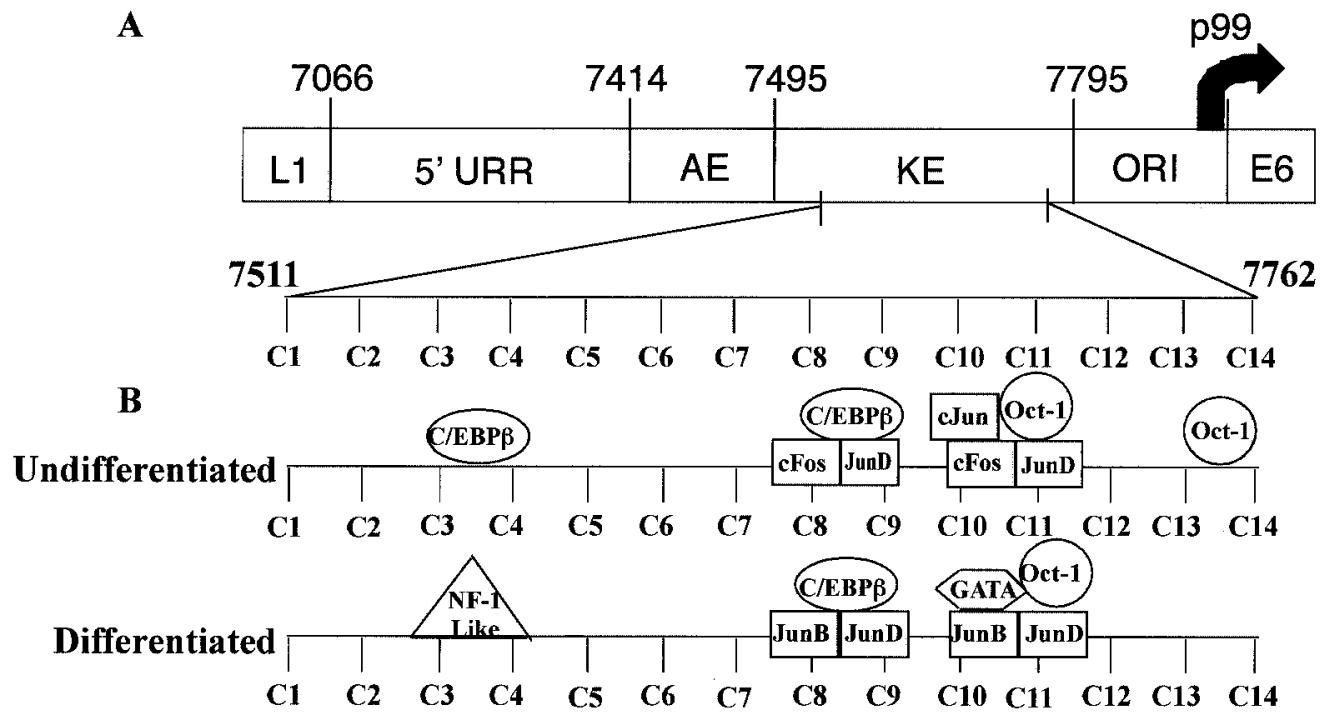

C1

C2

C3

C4

CAACTATGCTGATGCAGT AGTTCTGCGGTTTTTGGT TTCCTGAATACTAGTTTT TGCCAACATTCTGGCTTG C5 $\quad$ C6 $\quad C 7$ C8

TAGTTTCCTGCCTAACAC ACCTTGCCAACATATAAT CCAGTCCAACTTTGCAAT TATACTATGAATCATGTT

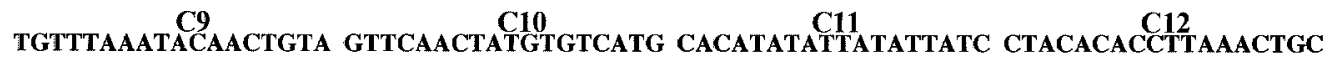
C13
TTTTAGGCACATATTTG TAGATTATCTATATCCTT

FIG. 1. HPV31 URR. (A) Map of the HPV31 URR, located between the end of the late gene L1 and the start of the early gene E6, showing the 252-bp region (nt 7511 to 7762) replaced by 14 linker scanning mutants. The positions of known URR elements, such as the 5' URR domain (nt 7066 to 7413), AE domain (nt 7414 to 7494), KE element (nt 7495 to 7789), the minimal origin of DNA replication (ORI), and the p99 promoter where the E6/E7 transcripts originate, are shown. C1 to C14 represent consecutive 18-bp sequences replaced by the NdeI-ApaI-BclI polylinker to generate the mutants described in this study. (B) Differential occupancy of the same cis regulatory element by alternative transcription factors under undifferentiated and differentiated cellular conditions. The nucleotide sequence (nt 7511 to 7762 ) of the KE region, indicating the identity of linkers $\mathrm{C} 1$ to $\mathrm{C} 14$, is also shown.

about $90 \%$ decrease in activity relative to the wild-type construct. While transfection of NHEK with mutants C2, C3, C6, C7, C9, and $\mathrm{C} 12$ decreased transcriptional activity by 70 to $80 \%$, mutants $\mathrm{C} 1, \mathrm{C} 4$, and $\mathrm{C} 11$ reduced activity by about 50 to $60 \%$ (Fig. 2A). The reduction in promoter activity observed suggests that we have mutated cis elements with a positive role in the regulation of early gene expression in the early stages of infection. It appears that more of the wild-type sequence is necessary for transcriptional regulation of p99 activity in NHEK than in 9E or C33A cells. The differences observed for p99 promoter activity with the linker scanning mutants in the three different cell types suggest that a difference in cell type and/or the presence of viral DNA and gene products influences the regulation of $\mathrm{p} 99$ promoter activity by the cis elements. Transfection experiments were repeated three to five times and demonstrated highly reproducible results.

KE region cis elements affecting $\mathbf{p 9 9}$ promoter activity upon differentiation. Having identified KE region cis elements important for viral transcriptional control during the initial stages of the viral life cycle, as modeled by monolayer culture, we next wanted to investigate the effect of these same viral KE cis elements on transcriptional control in differentiating host cells, which is where the late stages of the viral life cycle occur. Because suspension in methylcellulose is a simplified system for the induction of keratinocyte differentiation $(24,59)$, we utilized this system to discern the effect of host tissue differentiation on viral transcriptional control. Differentiation studies were first done with HPV31b-positive 9E cells to investigate the influence of viral gene products and viral replication on differentiation-dependent transcriptional activity. The ability of $9 \mathrm{E}$ cells to differentiate in methylcellulose has been well established $(24,59,62)$. Transfection of $9 \mathrm{E}$ cells with mutants $\mathrm{C} 2, \mathrm{C} 3, \mathrm{C} 7, \mathrm{C} 8, \mathrm{C} 10$, and $\mathrm{C} 14$ resulted in an about $90 \%$ reduction in activity upon differentiation compared to the wild type, while transfection with mutants $\mathrm{C} 1, \mathrm{C} 6, \mathrm{C} 9, \mathrm{C} 11, \mathrm{C} 12$, and $\mathrm{C} 13$ decreased transcriptional activity by 60 to $80 \%$ upon differentiation (Fig. 2B). However, transfection of 9E cells with mutants $\mathrm{C} 4$ and $\mathrm{C} 5$, with subsequent differentiation in methylcellulose, resulted in no significant change in promoter activity relative to the wild type (Fig. 2B).

To identify the specific effects that host tissue differentiation has on viral transcriptional regulation in 9E cells, we compared the results to those from the monolayer experiments (Table 3 ). The wild-type sequences replaced by mutants $\mathrm{C} 8$ and $\mathrm{C} 10$ act as strong constitutive positive regulators of E6/E7 expression, as transfection of $9 \mathrm{E}$ cells with these mutants decreases p99 activity by $90 \%$ or more under both undifferentiated and differentiated conditions. Though no marked difference in pro- 
A

FOLD CHANGE OVER WILD TYPE

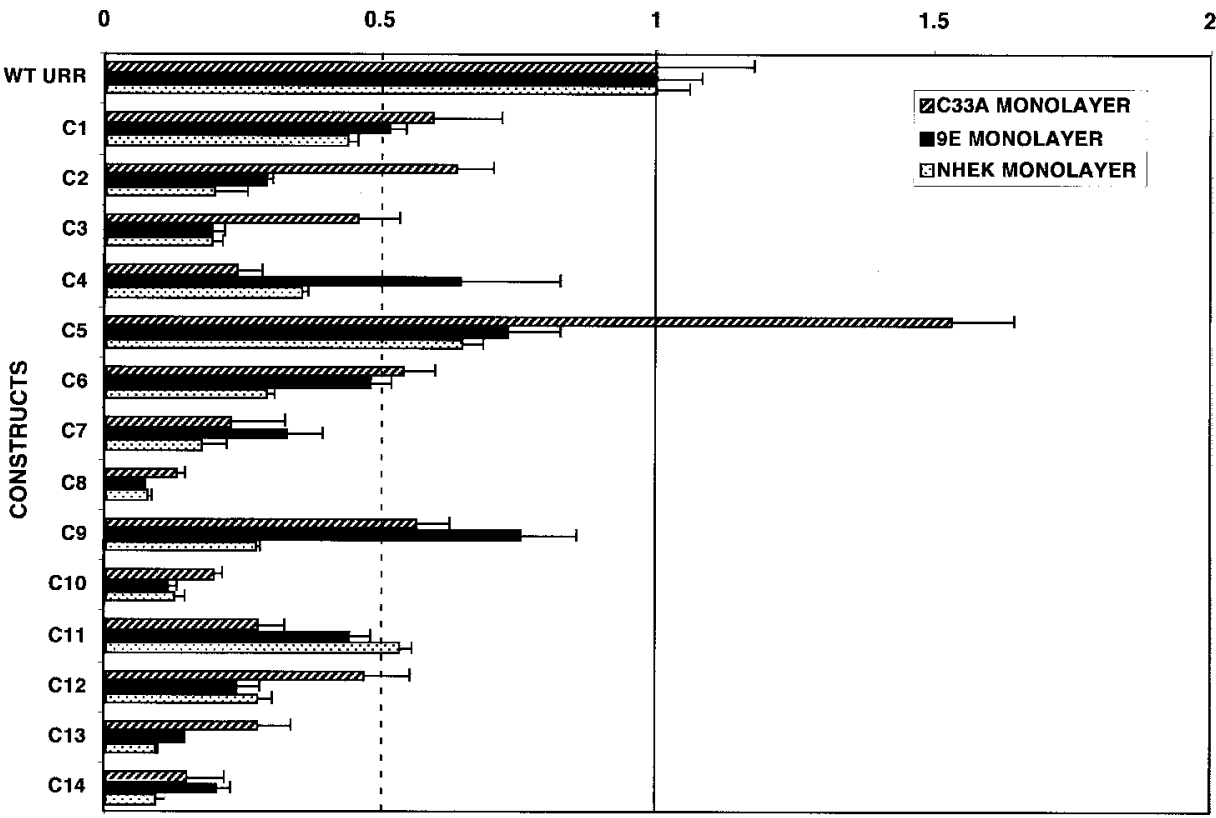

B

0.5

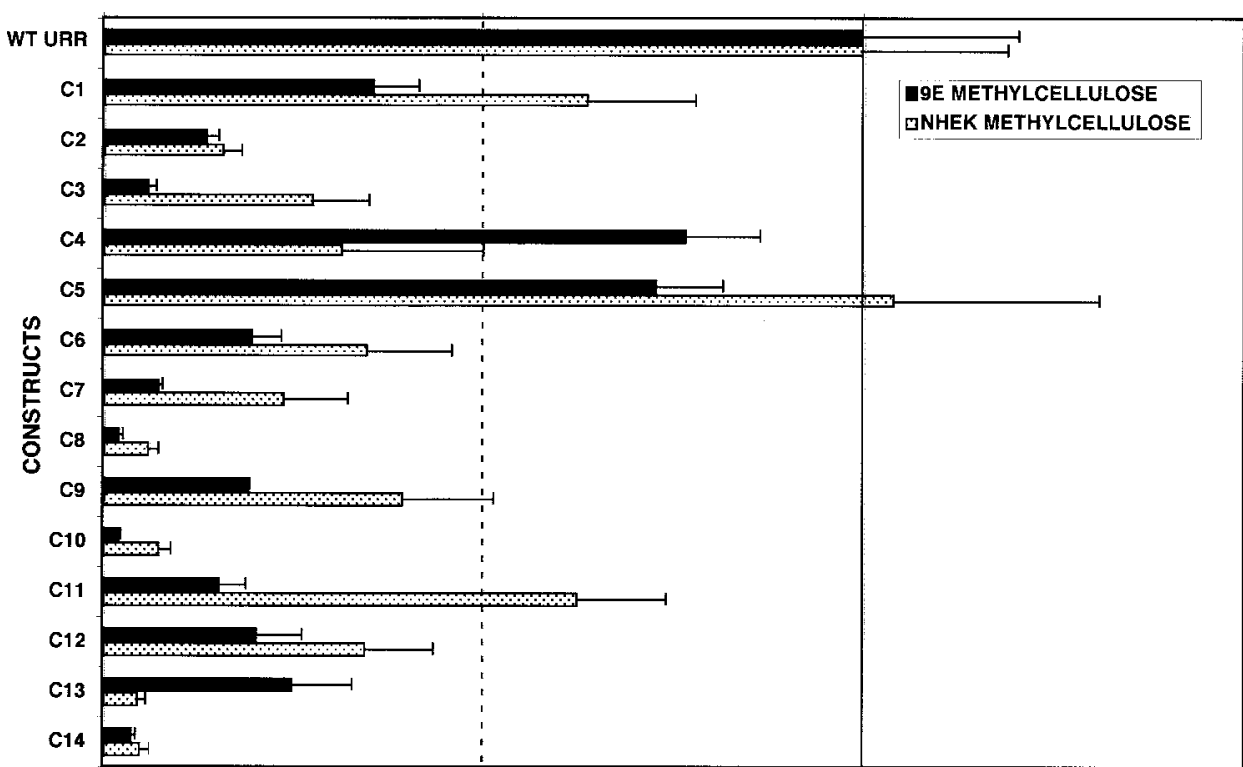

FIG. 2. Luciferase reporter assay. (A) Transcriptional regulation of $\mathrm{p} 99$ promoter activity by cis regulatory elements located within a 252-bp region (nt 7511 to 7762) of the HPV31 URR in monolayer cell cultures. C33A (stripes), CIN-612 9E (solid), and NHEK (dots) cells were transfected with $1 \mu \mathrm{g}$ of either the wild type or a C1 to C14 mutant URR luciferase reporter construct. For each linker scanning mutant, C1 to $\mathrm{C} 14$, the luciferase activity was expressed as the fold change over that of the wild-type construct, which was set to 1.00 . The solid line represents $100 \%$ of the wild-type activity. The dotted line represents $50 \%$ of the wild-type activity. Individual transfection experiments were done in duplicate and values are expressed as the means and standard deviations from at least three individual experiments. (B) Effect of host tissue differentiation on p99 transcriptional control by cis regulatory elements located within the URR. CIN-612 9E (solid) and NHEK (dots) cells were transfected as described in Materials and Methods. After transfection they were suspended in methylcellulose for $48 \mathrm{~h}$ and cell lysates were subsequently assayed for luciferase activity. The fold change in activity for each mutant construct over that of the wild-type URR was determined as described for panel A. The solid line represents $100 \%$ of the wild-type activity. The dotted line represents $50 \%$ of the wild-type activity. Results are expressed as the means and standard deviations from at least four individual experiments. 
TABLE 3. Comparison of the transcriptional regulation of p99 promoter activity by linker scanning mutants $\mathrm{C} 1$ to $\mathrm{C} 14$ between undifferentiated and differentiated CIN-612 9E and NHEK cultures

\begin{tabular}{|c|c|c|c|c|c|c|}
\hline \multirow{2}{*}{$\begin{array}{l}\text { Linker scanning } \\
\text { mutant (nt) }\end{array}$} & \multicolumn{4}{|c|}{$\begin{array}{l}\text { Fold change in activity of indicated cells compared to that } \\
\text { of wild type }{ }^{a}\end{array}$} & \multirow{2}{*}{$\begin{array}{l}\text { Known and putative binding sites } \\
\text { affected by each mutation }\end{array}$} & \multirow{2}{*}{$\begin{array}{l}\text { Factors previously } \\
\text { identified to bind to } \\
\text { these regions } \\
\text { (reference) }\end{array}$} \\
\hline & $9 \mathrm{E}(\mathrm{U})$ & 9E (D) & NHEK (U) & NHEK (D) & & \\
\hline C1 (7511-7528) & 0.51 & 0.36 & 0.44 & 0.64 & $\mathrm{AP}-1, \mathrm{C} / \mathrm{EBP}$ & \\
\hline C2 (7529-7546) & 0.29 & 0.14 & 0.20 & 0.16 & ICSBP & \\
\hline C3 (7547-7564) & 0.19 & 0.06 & 0.20 & 0.28 & NF-1, C/EBP, HNF-1 & NF-1-like factor $(40)$ \\
\hline C4 (7565-7582) & 0.64 & 0.76 & 0.36 & 0.32 & NF-1, C/EBP, HNF-1 & NF-1-like factor (40) \\
\hline C5 (7583-7600) & 0.73 & 0.73 & 0.65 & 1.04 & $\mathrm{C} / \mathrm{EBP}$ & \\
\hline C6 (7601-7618) & 0.48 & 0.20 & 0.29 & 0.35 & $\mathrm{C} / \mathrm{EBP}$ & \\
\hline C7 (7619-7636) & 0.33 & 0.07 & 0.18 & 0.24 & & \\
\hline C8 (7637-7654) & 0.07 & 0.02 & 0.08 & 0.06 & C/EBP, AP-1 & AP-1 (40) \\
\hline C9 (7655-7672) & 0.75 & 0.19 & 0.28 & 0.39 & $\mathrm{C} / \mathrm{EBP}$ & AP-1 (40) \\
\hline $\mathrm{C} 10(7673-7690)$ & 0.11 & 0.02 & 0.13 & 0.07 & AP-1, GATA-1, Oct-1, TBP, SRF & AP-1, Oct-1 (40) \\
\hline C11 (7691-7707) & 0.44 & 0.15 & 0.54 & 0.62 & GATA-1, Oct-1, TBP, SRF & AP-1, Oct-1 (40) \\
\hline C12 (7708-7725) & 0.24 & 0.20 & 0.28 & 0.34 & & \\
\hline C13 (7726-7743) & 0.14 & 0.25 & 0.09 & 0.05 & Oct-1, GATA-1 & \\
\hline C14 (7744-7762) & 0.21 & 0.04 & 0.09 & 0.05 & GATA-1 & \\
\hline
\end{tabular}

\footnotetext{
${ }^{a} \mathrm{U}$, undifferentiated; D, differentiated.

${ }^{b}$ Identified by TRANSFAC analysis.
}

moter activity was observed between undifferentiated and differentiated systems when $9 \mathrm{E}$ cells were transfected with most of the mutants, a significant decrease in promoter activity relative to monolayer culture was observed when $9 \mathrm{E}$ cells transfected with mutants $\mathrm{C} 7, \mathrm{C} 9$, and $\mathrm{C} 11$ were allowed to differentiate. These studies indicate that specific cis elements may make different contributions to transcriptional activity in an undifferentiated host cell environment versus a differentiated one.

NHEK were also transfected with the wild type and the linker scanning mutant constructs and were allowed to differentiate in methylcellulose $(1,59,62)$. While transfection with $\mathrm{C} 2, \mathrm{C} 8, \mathrm{C} 10, \mathrm{C} 13$, and $\mathrm{C} 14$ caused a severe reduction (80 to $90 \%$ ) in promoter activity compared to that of the wild-type construct upon differentiation, transfection of NHEK with mutants $\mathrm{C} 3, \mathrm{C} 4, \mathrm{C} 6, \mathrm{C} 7, \mathrm{C} 9$, and $\mathrm{C} 12$ resulted in a 60 to $70 \%$ reduction in promoter activity (Fig. $2 \mathrm{~B})$. The role of host tissue differentiation on viral transcriptional regulation was again evaluated by comparing data for NHEK under undifferentiated and differentiated host cell conditions (Table 3). Transfection with mutants $\mathrm{C} 5$ and $\mathrm{C} 11$ had no effect on the transcriptional regulation of $\mathrm{p} 99$ under both undifferentiated and differentiated host cell conditions. With the exception of mutants $\mathrm{C} 1, \mathrm{C} 5$, and $\mathrm{C} 11$, transfection of NHEK with all mutants resulted in a decrease in p99 activity of 60 to $>90 \%$ upon differentiation. In contrast to what was seen with $9 \mathrm{E}$ cells, no specific cis regulatory region was differentially affected by differentiation of NHEK. All transfection experiments were repeated four to five times and the results were reproducible.

A comparison of results obtained with 9E cells and NHEK provides insight into whether the presence of endogenous viral gene products and viral DNA replication influence the transcriptional regulation by cis elements in a differentiating system. Although the promoter activities seen upon transfection of 9E cells and NHEK with mutants C2, C8, C10, and C14 were similar, an increase of activity was observed in NHEK compared to $9 \mathrm{E}$ cells upon transfection with mutants $\mathrm{C} 1$ and $\mathrm{C} 9$ ( 2-fold), mutant C7 ( $\sim 3$-fold), and mutants C3 and C11
( $\sim$-fold). On the other hand, a 60 or $80 \%$ decrease in p99 activity was observed in NHEK compared to $9 \mathrm{E}$ cells when they were transfected with mutants $\mathrm{C} 4$ and $\mathrm{C} 13$, respectively. Together, these data suggest a role for viral gene products and/or viral DNA replication on transcription during the late stages of the viral life cycle.

Cellular proteins interacting with identified cis elements within the HPV31 KE region. Our search of the TRANSFAC database (75) has shown that the region of $\mathrm{C} 1$ to $\mathrm{C} 14$ (nt 7511 to 7762) contains numerous putative binding sites for several cellular transcription factors. Table 3 lists putative regulatory sites in the wild-type sequence that are replaced by linker scanning mutants $\mathrm{C} 1$ to $\mathrm{C} 14$. There is the potential that cis responsive elements are recognized not by a single factor, but rather by a set of abutting or overlapping related or unrelated factors acting positively or negatively on transcription (41). Therefore, we attempted to identify transcription factors that bind to the cis elements identified in the KE region under cellular conditions that represent different stages of the viral life cycle. To dissect the interplay of individual cis elements with cellular factors, in both the basal and differentiating cellular environments, we performed EMSAs using undifferentiated and differentiated 9E nuclear extracts and several DNA probes with nucleotide sequences corresponding to the wildtype sequence spanning the region of $\mathrm{C} 1$ to $\mathrm{C} 14$.

(i) $\mathbf{C 1}$ and C2. TRANSFAC analysis predicted C/EBP and AP-1 binding sites in the $\mathrm{C} 1$ region. The gel shift assay revealed the formation of potential protein-DNA complexes that were not competed by either cold homologous competitor or with AP-1 or C/EBP consensus oligonucleotides (data not shown). To determine whether the region C2 binds ICSBP, as predicted by the sequence search, an EMSA was again performed. A complex, C2 I, was observed with both undifferentiated and differentiated 9E nuclear extracts which was not competed by a 100 -fold excess of either the cold homologous competitor or ISCBP consensus oligonucleotide (Fig. 3).

(ii) $\mathbf{C 3 / C 4}$. The region $\mathrm{C} 3 / \mathrm{C} 4$ contains overlapping putative binding sites for NF-1, HNF-1, and C/EBP. When the binding 


\section{C2}

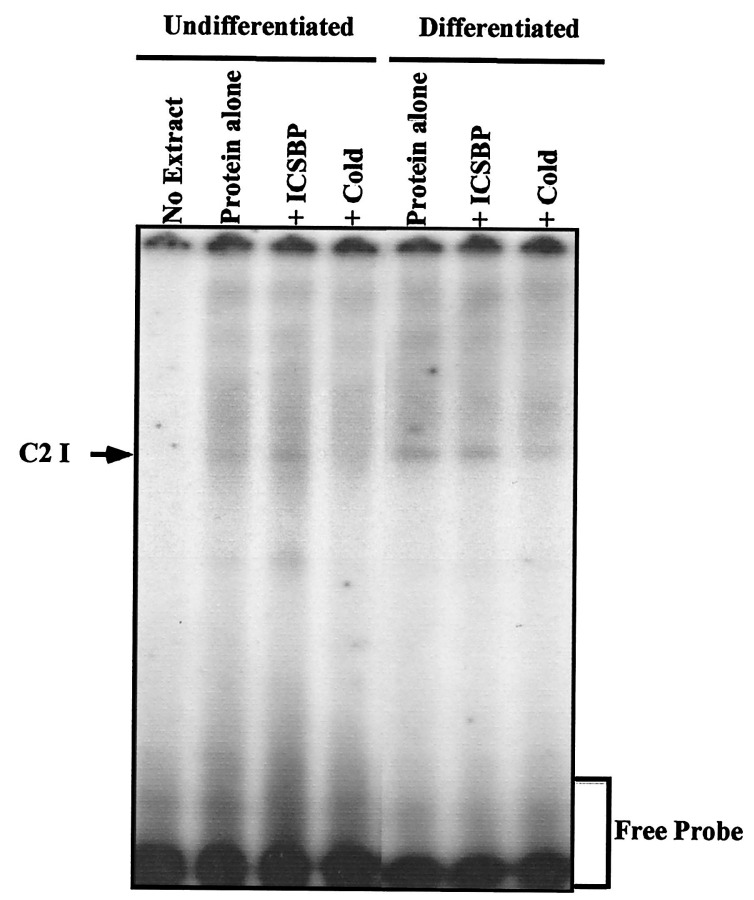

FIG. 3. Characterization of cellular factors that binds to the $\mathrm{C} 2$ region by EMSAs. ${ }^{32} \mathrm{P}$-labeled oligonucleotides corresponding to region $\mathrm{C} 2$ of the $\mathrm{KE}$ region were incubated with undifferentiated and differentiated CIN-612 9E nuclear extracts in the presence or absence of a 100-fold excess of competitors, as indicated. Specific DNA-protein complexes are shown. The probes and competitors used are described in Materials and Methods.

of cellular factors to the $\mathrm{C} 3 / \mathrm{C} 4$ region was examined by EMSA using a $\mathrm{C} 3 / \mathrm{C} 4$ probe and undifferentiated $9 \mathrm{E}$ nuclear extract, two specific complexes, uC3/C4 I and uC3/C4 II, were observed. These complexes were competed by a 100 -fold excess of unlabeled $\mathrm{C} 3 / \mathrm{C} 4$ and $\mathrm{C} / \mathrm{EBP}$ consensus oligonucleotides, but not by NF-1 and HNF-1 consensus oligonucleotides (Fig. 4A). Previous studies using HeLa nuclear extracts have shown that NF-1 does not bind to this region and that a novel factor binds to this region that is distinct from NF-1 (40). Our studies using undifferentiated $9 \mathrm{E}$ nuclear extracts showed only $\mathrm{C} / \mathrm{EBP}$ binding to this region.

$\mathrm{C} / \mathrm{EBP}$ belongs to the bZIP family of transcription factors (69) and is composed of several distinct members $(\mathrm{C} / \mathrm{EBP} \alpha$, $\mathrm{C} / \mathrm{EBP} \beta, \mathrm{C} / \mathrm{EBP} \delta, \mathrm{C} / \mathrm{EBP} \varepsilon$, and $\mathrm{CHOP})(56,72)$. In order to determine the expression profile of C/EBP family members in undifferentiated $9 \mathrm{E}$ nuclear extracts, we performed Western blot analysis. While three isoforms of $\mathrm{C} / \mathrm{EBP} \beta$ (C/EBP $\beta$ I, II, and III) were detected in undifferentiated $9 \mathrm{E}$ nuclear extracts by Western blot analysis, $\mathrm{C} / \mathrm{EBP} \alpha$ was absent (Fig. 5). It is known that three different translation initiation sites lead to the generation of three $\mathrm{C} / \mathrm{EBP} \beta$ isoforms, namely full-length $\mathrm{C} / \mathrm{EBP} \beta$ I, C/EBP $\beta$ II (or liver-enriched transcriptional activator protein [LAP]), and C/EBP $\beta$ III (or liver-enriched inhibitory protein [LIP]) $(21,66)$. For confirmation of the ability of $\mathrm{C} / \mathrm{EBP}$ to bind $\mathrm{C} 3 / \mathrm{C} 4$ in $9 \mathrm{E}$ monolayer extracts, EMSA was performed with antibodies specific for $\mathrm{C} / \mathrm{EBP} \alpha$ and $\mathrm{C} / \mathrm{EBP} \beta$.
The formation of complexes $\mathrm{uC} 3 / \mathrm{C} 4 \mathrm{I}$ and $\mathrm{uC} 3 / \mathrm{C} 4$ II was inhibited by antibody against $\mathrm{C} / \mathrm{EBP} \beta$ but was unaffected by antibody against $\mathrm{C} / \mathrm{EBP} \alpha$ (Fig. $4 \mathrm{~B}$ ). These assays confirm that $\mathrm{C} 3 / \mathrm{C} 4$ binds to $\mathrm{C} / \mathrm{EBP} \beta$ in undifferentiated $9 \mathrm{E}$ cells.

For identification of cellular factors that bind to $\mathrm{C} 3 / \mathrm{C} 4$ in differentiated 9E nuclear extracts, competition EMSA was performed, with a 100-fold excess of unlabeled homologous NF-1, HNF-1, and C/EBP consensus oligonucleotides as specific competitors. With differentiated $9 \mathrm{E}$ nuclear extracts, three complexes, dC3/C4 I, dC3/C4 II, and dC3/C4 III, were observed. All three complexes were competed by cold homologous competitor. The complex dC3/C4 II was competed by an unlabeled NF-1 consensus oligonucleotide, but not by $\mathrm{C} / \mathrm{EBP}$ and HNF-1 consensus oligonucleotides (Fig. 4A). Since the complexes $\mathrm{dC} 3 / \mathrm{C} 4 \mathrm{I}$ and $\mathrm{dC} 3 / \mathrm{C} 4$ III were not competed by NF-1, HNF-1, or C/EBP consensus oligonucleotide, it is possible that some other factor or factors binds to $\mathrm{C} 3 / \mathrm{C} 4$, giving rise to complexes $\mathrm{dC} 3 / \mathrm{C} 4 \mathrm{I}$ and $\mathrm{dC} 3 / \mathrm{C} 4$ III. Western blot analysis performed to determine the expression level of NF-1 in undifferentiated and differentiated 9E nuclear extracts indicated that NF-1 is not detectable in undifferentiated 9E cultures but is highly expressed upon differentiation (Fig. 5). It is plausible that the increase in NF-1 level following differentiation could have resulted in the formation of complex $\mathrm{dC} 3 / \mathrm{C} 4$ II. However, the complex dC3/C4 II was neither eliminated nor supershifted in the presence of antibody against NF-1 (data not shown), suggesting that $\mathrm{dC} 3 / \mathrm{C} 4$ II is bound by an NF-1-like factor that recognizes the NF-1 consensus sequence in a differentiated environment, but is distinct from NF-1. It is possible that other factors binding to the region $\mathrm{C} 3 / \mathrm{C} 4$ could have hindered the accessibility of NF-1 antibody to $\mathrm{C} 3 / \mathrm{C} 4$.

Since $\mathrm{C} / \mathrm{EBP}$ family members are expressed in a differentiation-dependent manner in the epidermis (43), it is possible that an altered expression pattern of C/EBP following differentiation could have accounted for the inability of $\mathrm{C} / \mathrm{EBP}$ to bind $\mathrm{C} 3 / \mathrm{C} 4$. While $\mathrm{C} / \mathrm{EBP} \alpha$ was not detectable in the differentiated $9 \mathrm{E}$ nuclear extract, Western blot analysis revealed a decrease in the expression level of $\mathrm{C} / \mathrm{EBP} \beta$ isoforms I, II, and III upon differentiation (Fig. 5). Therefore, the inability of $\mathrm{C} 3 / \mathrm{C} 4$ to bind $\mathrm{C} / \mathrm{EBP} \beta$ in differentiated $9 \mathrm{E}$ cells could be due to changes in the levels of the $\mathrm{C} / \mathrm{EBP} \beta$ isoforms that decreased the overall availability for binding $\mathrm{C} 3 / \mathrm{C} 4$. It is known that the abundance of $\mathrm{C} / \mathrm{EBP} \beta$ isoforms is dependent on the cell differentiation state and that changes in the ratio of different isoforms determine the ability of $\mathrm{C} / \mathrm{EBP} \beta$ to regulate transcription (21). Studies have also shown that full-length $\mathrm{C} / \mathrm{EBP} \beta$ and LAP act as activators and that LIP acts as a repressor on the HPV16 long control region (LCR) (66). Based on competition gel shift assay results, we conclude that some unidentified factor(s), in addition to the NF-1-like factor, binds to the $\mathrm{C} 3 / \mathrm{C} 4$ region in differentiated $9 \mathrm{E}$ cells, resulting in the formation of complexes $\mathrm{dC} 3 / \mathrm{C} 4 \mathrm{I}$ and $\mathrm{dC} 3 / \mathrm{C} 4 \mathrm{III}$. It is possible that this unknown factor could have prevented $\mathrm{C} / \mathrm{EBP} \beta$ from binding to the $\mathrm{C} 3 / \mathrm{C} 4$ region under differentiated cellular conditions.

(iii) C5/C6 and C7. TRANSFAC analysis predicted a weak putative $\mathrm{C} / \mathrm{EBP}$ binding site (having $<50 \%$ homology with the $\mathrm{C} / \mathrm{EBP}$ consensus sequence) overlapping regions C5 and C6. When labeled C5/C6 oligonucleotide was incubated with un- 
A $\mathrm{C3} / \mathrm{C} 4$

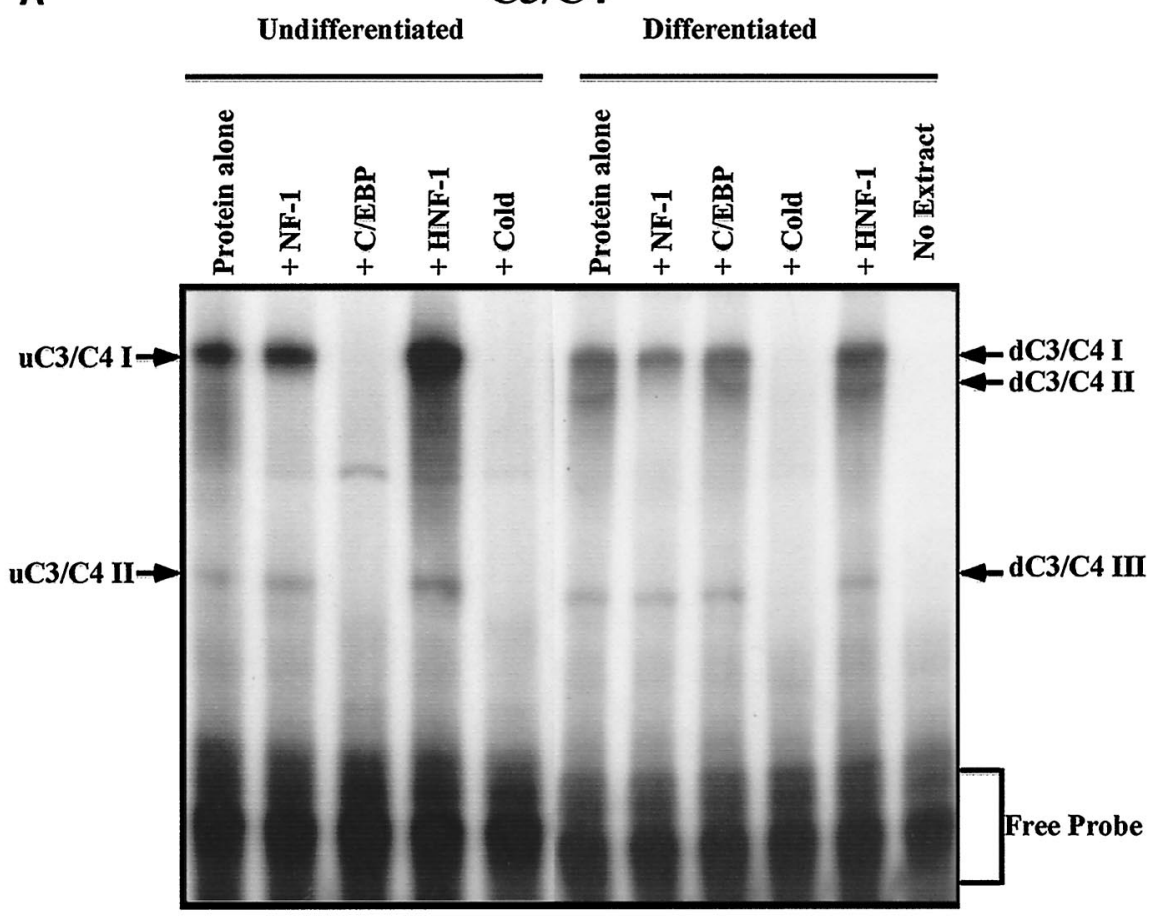

B

\section{$\mathrm{C3} / \mathrm{C} 4$}

Undifferentiated

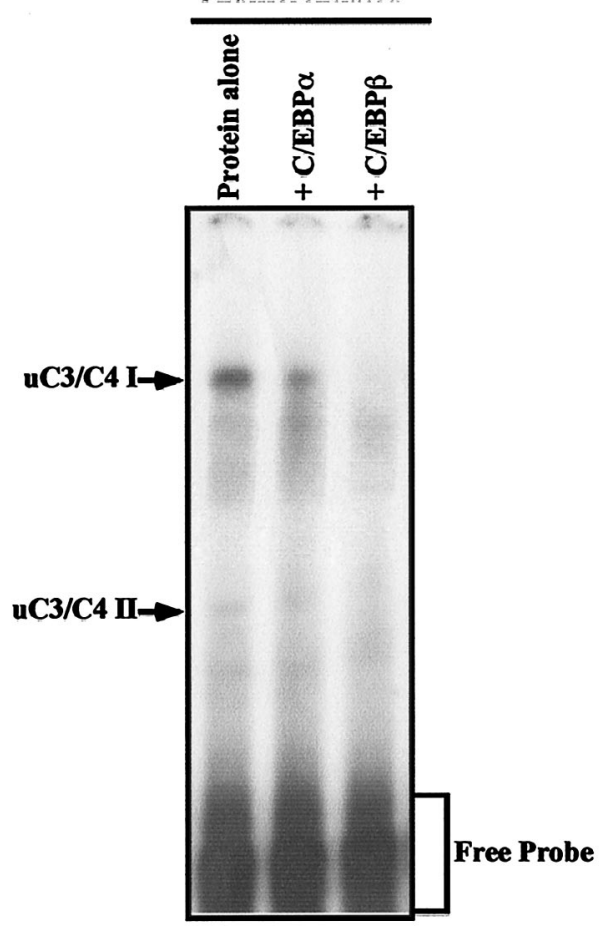

differentiated and differentiated 9E nuclear extracts, several potential DNA-protein complexes were observed. None of these complexes were competed by cold C5/C6 or C/EBP consensus oligonucleotides, indicating the nonspecific nature of
FIG. 4. Electrophoretic mobility shift analysis showing the binding specificity of $\mathrm{C} 3 / \mathrm{C} 4$ to cellular factors present in undifferentiated and differentiated CIN-612 9E nuclear extracts. The C3/C4 probe was incubated with undifferentiated or differentiated 9E nuclear extracts in the presence or absence of competitors (A) or antibodies (B), as indicated. Specific DNA-protein complexes are shown. The probes and competitors used are described in Materials and Methods.

the interaction (Fig. 6). No putative transcription factor binding sites were predicted for the $\mathrm{C} 7$ region by the sequence search. Nonetheless, competition EMSA was performed, with the consensus binding sequence for several transcription factors as competitors, with both undifferentiated and differentiated 9E nuclear extracts. Very faint, almost undetectable bands were observed under both conditions which were not competed by unlabeled C7 oligonucleotide (data not shown). These gel shift assays indicate that the region of C5 through C7 does not bind any cellular transcription factor with specificity.

(iv) C8/C9. The TRANSFAC analysis predicted that the C8 region contains an $\mathrm{AP}-1$ site that abuts the $\mathrm{C} 9$ region and that the $\mathrm{C} 8 / \mathrm{C} 9$ region contains an overlapping $\mathrm{C} / \mathrm{EBP}$ binding site. To investigate whether this region binds AP-1, C/EBP, or both, we performed competition assays using labeled C8/C9 as probe. With an undifferentiated $9 \mathrm{E}$ nuclear extract, three specific DNA protein complexes, uC8/C9 I, uC8/C9 II, and uC8/C9 III, were observed (Fig. 7A). The complexes uC8/C9 I, II, and III were competed by a 100-fold excess of cold C8/C9 and AP-1 consensus oligonucleotides (Fig. 7A). Because the competition of complexes $\mathrm{uC} 8 / \mathrm{C} 9 \mathrm{I}$, II, and III in the presence of cold $\mathrm{C} / \mathrm{EBP}$ consensus oligonucleotide was not strong, EMSAs were performed in the presence of antibodies against $\mathrm{C} / \mathrm{EBP} \alpha$ and $\mathrm{C} / \mathrm{EBP} \beta$ to investigate whether $\mathrm{C} 8 / \mathrm{C} 9$ binds $\mathrm{C} / \mathrm{EBP}$ in extracts from undifferentiated $9 \mathrm{E}$ cells. The forma- 


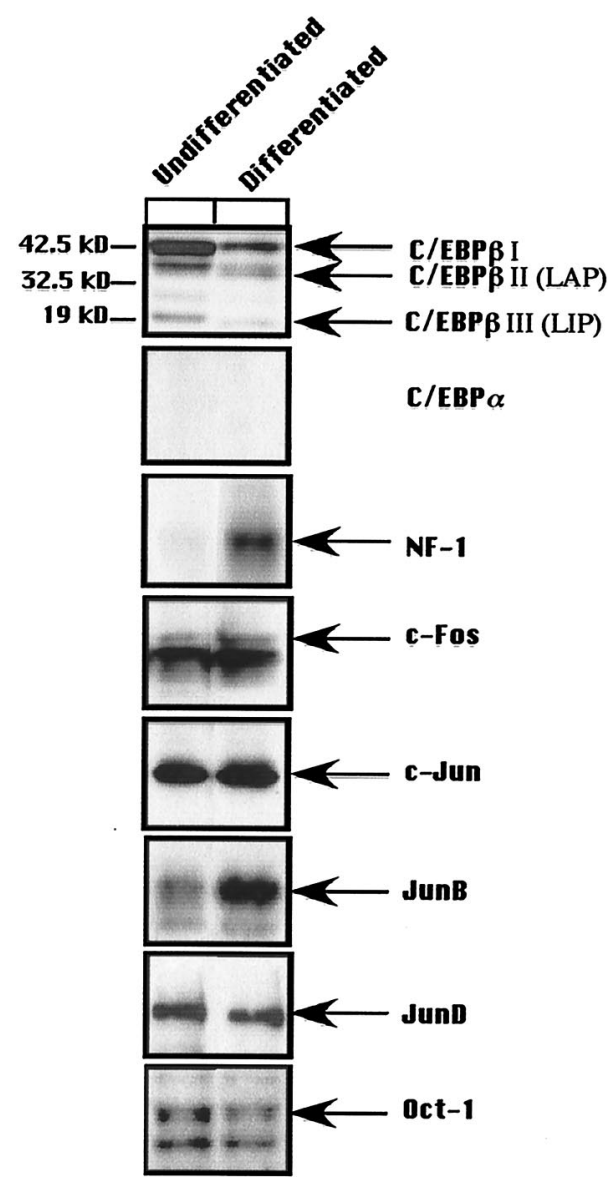

FIG. 5. Expression of AP-1, NF-1, C/EBP, and Oct-1 proteins in undifferentiated and differentiated CIN-612 9E nuclear extracts. Western blot analysis with antibodies specific for $\mathrm{C} / \mathrm{EBP} \alpha, \mathrm{C} / \mathrm{EBP} \beta, \mathrm{NF}-1$, c-Fos, JunB, c-Jun, JunD, and Oct-1 was performed with $15 \mu \mathrm{g}$ of nuclear extracts from undifferentiated and differentiated CIN-612 9E cells.

tion of complexes $\mathrm{uC} 8 / \mathrm{C} 9 \mathrm{I}, \mathrm{uC} 8 / \mathrm{C} 9 \mathrm{II}$, and $\mathrm{uC} 8 / \mathrm{C} 9$ III was inhibited by antibody against $\mathrm{C} / \mathrm{EBP} \beta$, but was unaffected by antibody against $\mathrm{C} / \mathrm{EBP} \alpha($ Fig. $7 \mathrm{~B})$. These assays indicate that $\mathrm{AP}-1$ and $\mathrm{C} / \mathrm{EBP} \beta$ bind to the $\mathrm{C} 8 / \mathrm{C} 9$ site in undifferentiated $9 E$ cells. Previous studies have also shown that part of the C8/C9 region (designated FPIII, spanning nt 7640 to 7656 ) binds AP-1 (40).

To investigate whether the binding pattern changes with host tissue differentiation, competition EMSA was performed using a differentiated 9E nuclear extract and $\mathrm{C} 8 / \mathrm{C} 9$ as the probe. For the differentiated environment, we consistently observed the formation of four distinct complexes, dC8/C9 I, dC8/C9 II, dC8/C9 III, and dC8/C9 IV (Fig. 7A). Besides these distinct complexes, we occasionally observed the formation of several other less distinct complexes, dC8/C9 V, dC8/C9 VI, and dC8/C9 VII. All of these complexes were abolished by the addition of cold homologous competitor and AP-1 consensus oligonucleotide (Fig. 7A). When cold C/EBP consensus oligonucleotide was used as a competitor, the complexes dC8/C9 I and dC8/C9 II migrated as two separate bands and none of the other complexes were abolished (Fig. 7A). This result suggests

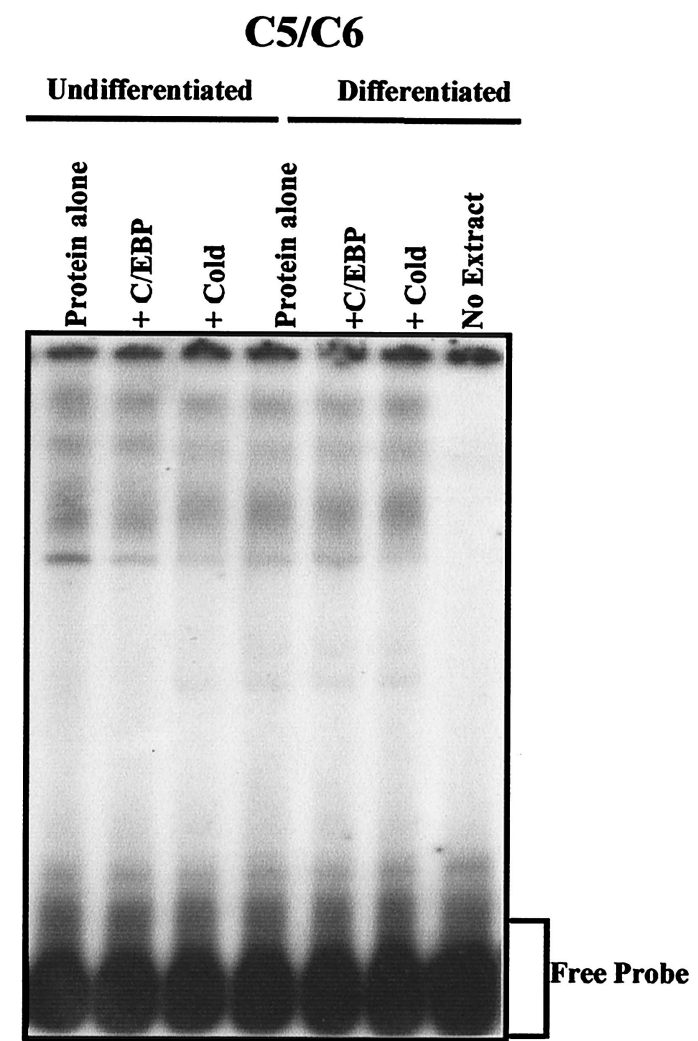

FIG. 6. EMSA showing the lack of specific factor interaction with the $\mathrm{C} 5 / \mathrm{C} 6$ region under different cellular conditions. Undifferentiated and differentiated $9 \mathrm{E}$ nuclear extracts were incubated with ${ }^{32} \mathrm{P}$-labeled C5/C6 oligonucleotides in the absence or presence of a 100-fold excess of competitors, as indicated.

that besides AP-1, C/EBP may be a part of the complex that binds to $\mathrm{C} 8 / \mathrm{C} 9$ in differentiated $9 \mathrm{E}$ nuclear extracts. When EMSA was performed using antibodies against $\mathrm{C} / \mathrm{EBP} \alpha$ and $\mathrm{C} / \mathrm{EBP} \beta$, the complex $\mathrm{dC} 8 / \mathrm{C} 9$ I was abolished by the addition of $\mathrm{C} / \mathrm{EBP} \beta$ antibody, indicating that $\mathrm{C} / \mathrm{EBP} \beta$ binds to the $\mathrm{C} 8 / \mathrm{C} 9$ region under differentiated conditions (Fig. 7B). $\mathrm{C} / \mathrm{EBP} \beta$ not only forms dimers with other $\mathrm{C} / \mathrm{EBP}$ family members (69) and their truncated isoforms (20), but it is also known to complex with AP-1 family members (29). Whether C/EBP $\beta$ binds to $\mathrm{C} 8 / \mathrm{C} 9$ as a homodimer, a heterodimer with AP-1 family members, or both remains unclear.

The AP-1 transcription factors are composed of Jun family members (c-Jun, JunB, and JunD) that can form either homoor heterodimers among themselves. Jun proteins also dimerize with Fos family members (c-Fos, FosB, Fra1, and Fra2) $(3,35)$. Additionally, Jun and Fos proteins can also dimerize efficiently with other bZIP proteins (17), and the various potential AP-1 dimers differ in their DNA binding affinities and specificities (7). In order to determine the composition of the AP-1 complex that binds $\mathrm{C} 8 / \mathrm{C} 9$ under different cellular conditions, we performed EMSAs in the presence of antibodies against c-Fos, JunB, c-Jun, and JunD. While the addition of c-Fos and JunD antibodies abolished the formation of complexes uC8/C9 II and $\mathrm{uC} 8 / \mathrm{C} 9 \mathrm{III}$, no such disruption of complex formation was observed in the presence of JunB and c-Jun antibodies (Fig. 7C). We conclude that the c-Fos/JunD heterodimer binds to 

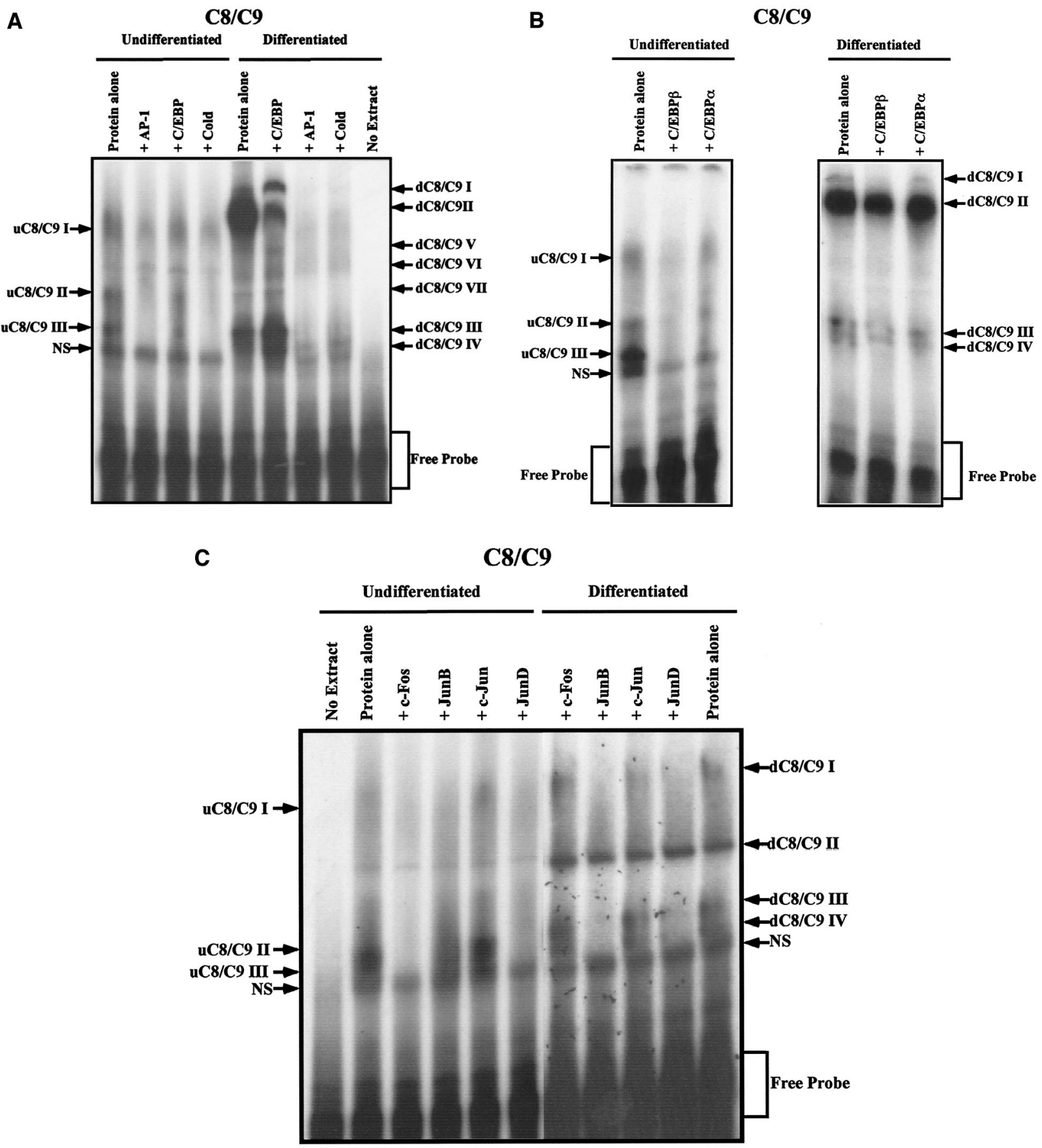

FIG. 7. EMSA confirming specific binding of C/EBP and AP-1 to the C8/C9 region. Undifferentiated and differentiated 9E nuclear extracts were incubated with ${ }^{32} \mathrm{P}$-labeled $\mathrm{C} 8 / \mathrm{C} 9$ in the presence or absence of a 100-fold excess of competitors (A), as indicated, with antibodies against $\mathrm{C} / \mathrm{EBP} \alpha$ and $\mathrm{C} / \mathrm{EBP} \beta$ (B), or with specific antibodies directed against AP-1 family members c-Fos, JunB, c-Jun, and JunD (C). Specific DNA protein complexes and nonspecific (NS) complexes are indicated.

C8/C9 in undifferentiated 9E nuclear extracts. Using HeLa cell extracts, others have observed that this region binds c-Fos and JunD, whereas JunD was observed to be the primary constituent binding to this region in a $9 \mathrm{E}$ cell monolayer (40). Moreover, the components of the AP-1 family members that bind to this site vary with the cell line examined (40). When EMSA was performed using differentiated $9 \mathrm{E}$ nuclear extract, the com- plexes dC8/C9 I, dC8/C9 III, and dC8/C9 IV were abolished by the addition of JunB and JunD antibodies, while the addition of antibodies against c-Fos and c-Jun had no effect on the formation of the complexes (Fig. 7C). Therefore, the JunB/ JunD heterodimer seems to have replaced the c-Fos/JunD heterodimer in differentiated $9 \mathrm{E}$ cells as the predominant AP-1 component that binds to the $\mathrm{C} 8 / \mathrm{C} 9$ region. The addition 
of JunD antibody resulted in either a clear elimination of the complexes dC8/C9 I, dC8/C9 III, and dC8/C9 IV (Fig. 7C) or, sometimes, a faint supershift (data not shown). The faint supershift presumably reflects heterodimerization products of JunD with other members of the Jun family, possibly JunB. These experiments suggest that JunB and JunD are the predominant AP-1 components binding to the $\mathrm{C} 8 / \mathrm{C} 9$ region in differentiated 9E cells. Quantitative differences in the elimination of in vitro DNA-protein bound complexes could be due to a number of factors, including the affinities and stabilities of different types of complexes involving interactions with antibodies and the protein or the interactions of the proteins with the DNA probe, as reported previously (68). Our results demonstrate that different members of the AP-1 family of transcription factors binds to $\mathrm{C} 8 / \mathrm{C} 9$ during different stages of the viral life cycle, and the differences between the undifferentiated and differentiated conditions are reproducible. However, $\mathrm{C} / \mathrm{EBP} \beta$ binds to $\mathrm{C} 8 / \mathrm{C} 9$ under both undifferentiated and differentiated conditions. Since $\mathrm{C} / \mathrm{EBP} \beta$ is known to form homodimers and heterodimers with bZIP family members (69), it is possible that formation of different heterodimers between $\mathrm{AP}-1$ family members and $\mathrm{C} / \mathrm{EBP} \beta$ could increase the repertoire of transcription factors that bind to $\mathrm{C} 8 / \mathrm{C} 9$. It is conceivable that the DNA binding specificities of different $\mathrm{C} / \mathrm{EBP} \beta$ AP-1 heterodimers will be different from that of a $\mathrm{C} / \mathrm{EBP} \beta$ homodimer, a JunB homodimer, a JunB/JunD heterodimer, or a Fos/Jun heterodimer. Therefore, the multiple protein-DNA complexes that are formed on $\mathrm{C} 8 / \mathrm{C} 9$ could be the culmination of different bZIP homo- and heterodimers binding to the same region.

To determine whether decreased expression of c-Fos in differentiated cells could have accounted for the absence of c-Fos within the AP-1 complex, we performed Western blot analysis to measure the expression level of AP-1 family members under different cellular conditions (Fig. 5). It was interesting that upon differentiation, c-Fos expression not only did not decrease, but it increased slightly (Fig. 5). Most notably, the level of JunB was strongly elevated upon differentiation (Fig. 5). This suggests that the absence of c-Fos in the AP-1 complex that binds to $\mathrm{C} 8 / \mathrm{C} 9$ in differentiated $9 \mathrm{E}$ nuclear extracts cannot be attributed to a decrease in its expression, but rather to the elevation of the JunB level. This increase in the level of JunB could result in the alteration of dimerization partners that bind to $\mathrm{C} 8 / \mathrm{C} 9$ under differentiated conditions. Western blot analysis also revealed comparable levels of JunD expression in undifferentiated and differentiated 9E cells (Fig. 5).

(v) C10/C11. Computer-assisted sequence analysis predicted AP-1, GATA-1, Oct-1, SRF, and TBP binding sites in the $\mathrm{C} 10 / \mathrm{C} 11$ region. When the ability of the $\mathrm{C} 10 / \mathrm{C} 11$ region to bind cellular factors was examined by EMSA using a corresponding C10/C11 probe and undifferentiated 9E nuclear extract, four specific complexes, designated uC10/C11 I, uC10/ C11 II, uC10/C11 III, and uC10/C11 IV, were formed (Fig. $8 \mathrm{~A})$. The complexes $\mathrm{uC} 10 / \mathrm{C} 11 \mathrm{II}$ and $\mathrm{uC} 10 / \mathrm{C} 11$ III were competed by a 100 -fold excess of unlabeled $\mathrm{C} 10 / \mathrm{C} 11$, AP-1, and Oct-1 consensus oligonucleotides, but not GATA, SRF, and TBP consensus oligonucleotides. The intensity of complex $\mathrm{uC} 10 / \mathrm{C} 11$ I increased following the addition of Oct-1 and SRF consensus oligonucleotides (Fig. 8A).

To dissect the individual components of the AP-1 complex, we performed EMSA, using specific antibodies against different members of the Jun/Fos family. The elimination of complexes uC10/C11 II, uC10/C11 III, and uC10/C11 IV was observed in the presence of c-Fos, c-Jun, and JunD antibodies and was also accompanied in each case by the appearance of another complex, uC10/C11 V (Fig. 8B). This suggests that c-Fos, c-Jun, and JunD are all involved in the formation of the AP-1 complex in undifferentiated 9E cells and that depletion of any of these three proteins by a specific antibody could alter the heterodimerization pattern of the other two partners, either between themselves or between other bZIP family members, thus giving rise to a new DNA-protein complex (uC10/ $\mathrm{C} 11 \mathrm{~V}$ ). However, the presence of JunB antibody had no effect on the formation of the complexes (Fig. 8B). The complexes $\mathrm{uC10/C11} \mathrm{II,} \mathrm{uC10/C11} \mathrm{III,} \mathrm{and} \mathrm{uC10/C11} \mathrm{IV} \mathrm{were} \mathrm{also} \mathrm{abol-}$ ished in the presence of antibody against Oct-1. As seen for EMSA using antibodies against c-Fos, c-Jun, and JunD, the disappearance of complexes uC10/C11 II, uC10/C11 III, and $\mathrm{uC} 10 / \mathrm{C} 11 \mathrm{IV}$ in the presence of Oct-1 antibody was also accompanied by the appearance of another band, for complex uC10/C11 V (Fig. 8B). We conclude from these experiments that AP-1 (c-Fos, c-Jun, and JunD heterodimers) and Oct-1 bind to $\mathrm{C} 10 / \mathrm{C} 11$ either alone or in combination. Kyo et al. have also reported simultaneous binding of JunD/c-Fos heterodimer and Oct- 1 to the $\mathrm{C} 10 / \mathrm{C} 11$ region (nt 7678 to 7700 ) in HeLa cell extracts (40).

To identify cellular factors that bind the $\mathrm{C} 10 / \mathrm{C} 11$ region in differentiated 9E cells, we performed competition EMSA, using $\mathrm{C} 10 / \mathrm{C} 11$ as the probe. With differentiated 9E nuclear extract, four complexes, dC10/C11 I, dC10/C11 II, dC10/C11 III, and $\mathrm{dC} 10 / \mathrm{C} 11 \mathrm{IV}$, were observed (Fig. 8A). An additional band, dC10/C11 V, appears following competition. The addition of unlabeled C10/C11, AP-1, and GATA consensus oligonucleotides abolished complexes dC10/C11 II, dC10/C11 III, and $\mathrm{dC} 10 / \mathrm{C} 11 \mathrm{IV}$. While the intensity of complexes dC10/C11 II, dC10/C11 III, and dC10/C11 IV was reduced and slightly shifted by the addition of cold Oct-1 consensus oligonucleotide, the addition of SRF and TBP consensus oligonucleotides had no effect on the formation of these complexes. The intensity of complex $\mathrm{dC} 10 / \mathrm{C} 11$ I was reduced in the presence of unlabeled self, AP-1, Oct-1, and GATA consensus oligonucleotides (Fig. 8A). This result indicates that besides AP-1 and GATA, Oct-1 may form a part of the complex that binds to the $\mathrm{C} 10 / \mathrm{C} 11$ region in differentiated $9 \mathrm{E}$ nuclear extracts.

A gel shift assay using antibodies against Jun/Fos members of the AP-1 family was carried out to detect any variation in the components of the AP-1 complex that binds to C10/C11 upon differentiation. While the complex $\mathrm{dC} 10 / \mathrm{C} 11$ I was clearly abolished by the JunB antibody, the complex was slightly inhibited by the JunD antibody (Fig. 8B). On the other hand, the addition of c-Fos and c-Jun antibodies not only failed to abolish the complex $\mathrm{dC} 10 / \mathrm{C} 11 \mathrm{I}$, but on the contrary increased the formation of the complex significantly (Fig. 8B). This indicates that c-Fos and c-Jun might prevent other AP-1 components (in this case, JunB and JunD) from binding to C10/C11. The addition of JunB antibody abolished the formation of complex dC10/C11 I (Fig. 8B). While competition gel shift assays demonstrated that the addition of cold AP-1 consensus oligonucleotide inhibits the formation of complexes dC10/C11 II, III, and IV and diminishes the intensity of complex dC10/C11 I (Fig. 
A

\section{C10/C11}

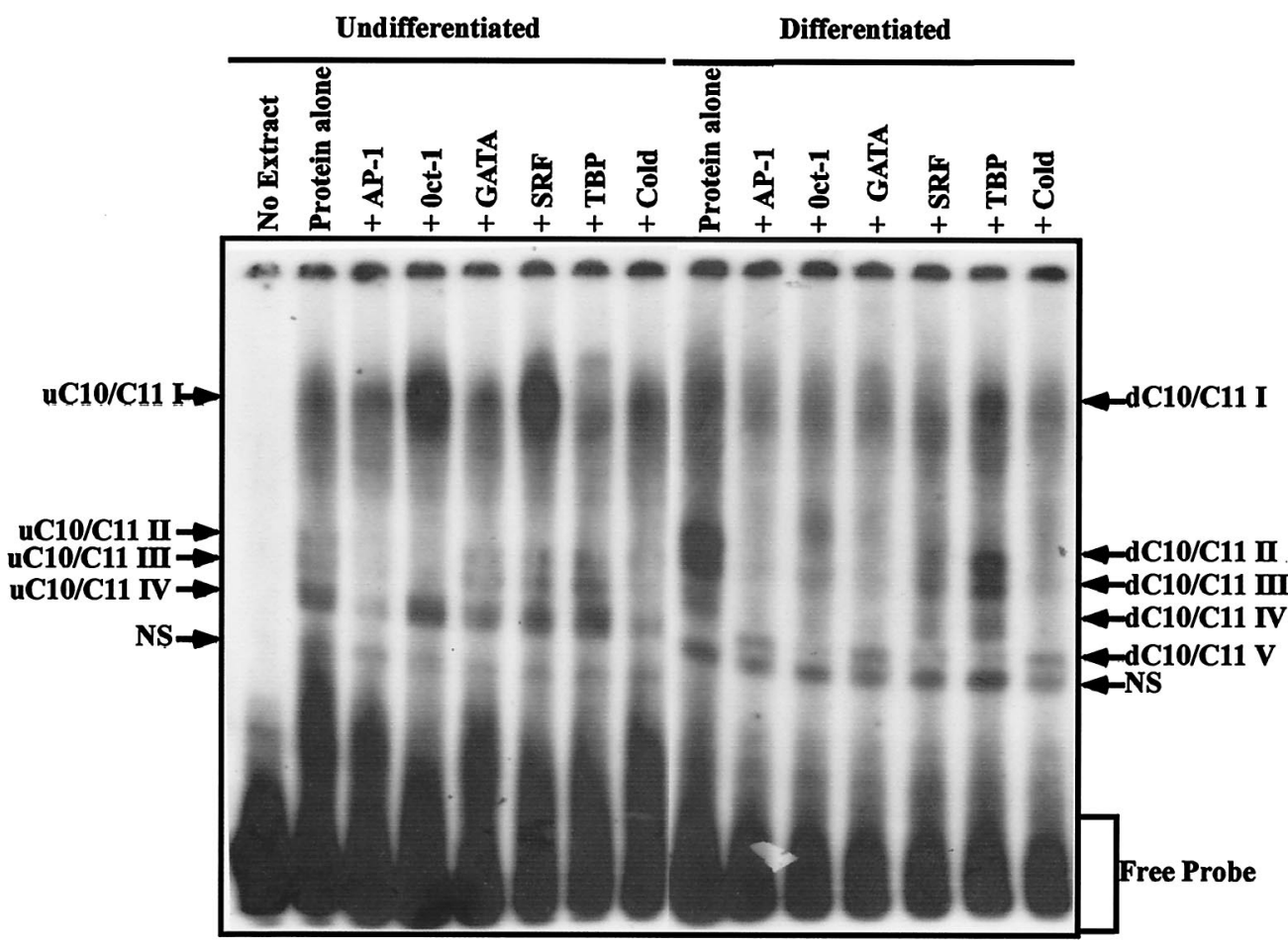

B

C10/C11

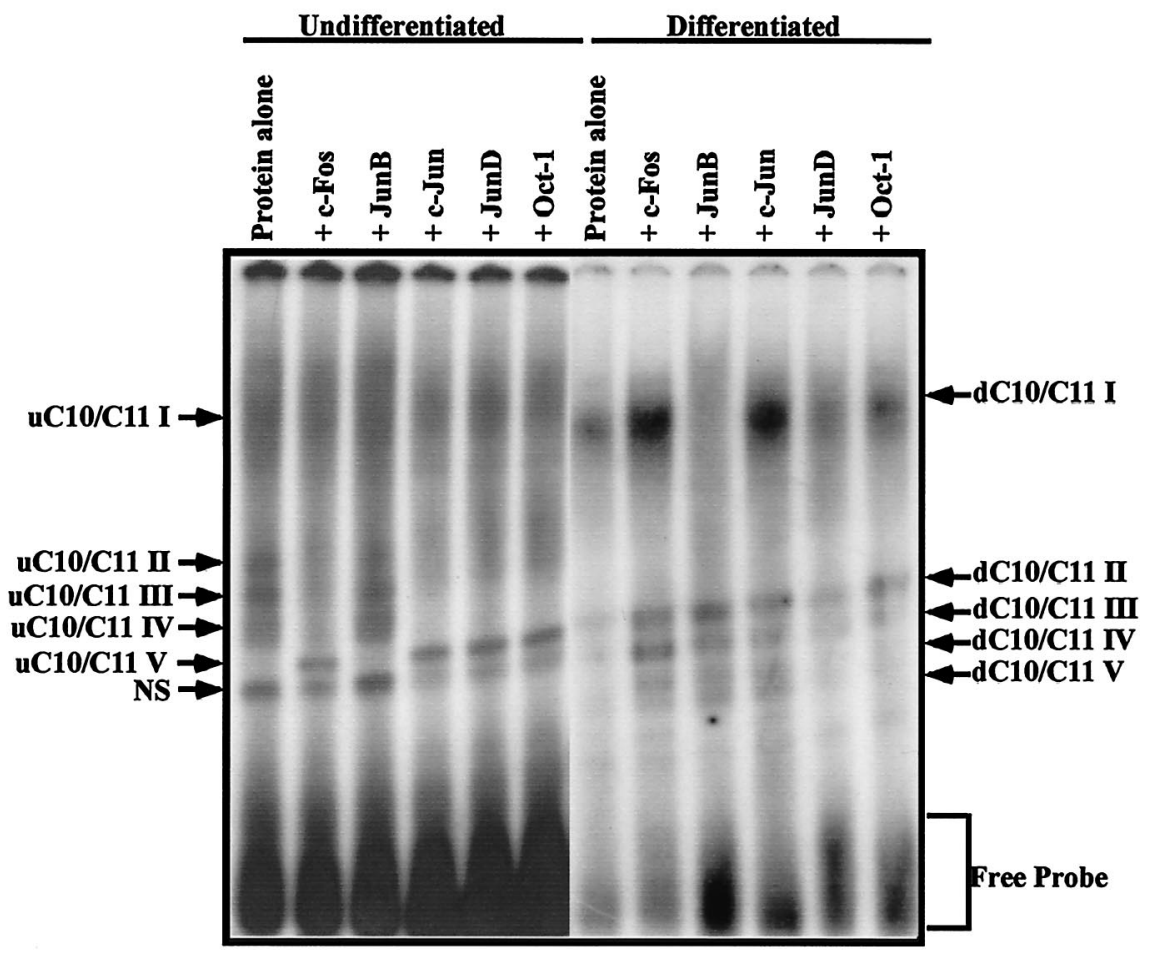

FIG. 8. Specific binding of cellular factors to the $\mathrm{C} 10 / \mathrm{C} 11$ region, as demonstrated by electrophoretic mobility shift analysis. The $\mathrm{C} 10 / \mathrm{C} 11$ probe was incubated with undifferentiated and differentiated 9E nuclear extracts in the presence or absence of a 100-fold excess of competitors (A), as indicated, or with specific antibodies directed against AP-1 family members c-Fos, JunB, c-Jun, and JunD as well as Oct-1 (B). Specific DNA protein complexes and nonspecific (NS) complexes are indicated. 
8A), EMSA performed with antibodies against JunB greatly diminished the complex dC10/C11 I and had no significant effect on the formation of complexes dC10/C11 II, III, and IV (Fig. 8B). These differences in the elimination of different DNA-protein complexes could be due to varying stabilities of different types of complexes involving interactions with antibodies and the protein as well as interactions between proteins and the DNA probe, as suggested previously. EMSA using Oct-1 antibody demonstrated either a slight increase in the intensity of complexes dC10/C11 II and dC10/C11 III (Fig. 8B) or had no effect on the formation of the complexes (data not shown). Because Oct-1 possesses an intrinsic ability to form protein-protein contacts (65), it is possible that Oct-1 functions as a transcriptional modulator by tethering transcriptional regulators AP-1 and GATA to region C10/C11 without directly interacting with the DNA under differentiated cellular conditions. Nonetheless, it is evident that $\mathrm{C} 10 / \mathrm{C} 11$ binds $\mathrm{AP}-1$ and that the heterodimerization pattern of AP-1 family members that bind to the $\mathrm{C} 10 / \mathrm{C} 11$ region changes upon differentiation. In contrast to what is seen with undifferentiated 9E cells, JunB was found to be the predominant AP-1 component that binds C10/C11 in differentiating 9E cells, either as a homodimer or a JunB/JunD heterodimer. Therefore, differentiation of 9E cells changes the AP- 1 components that bind to $\mathrm{C} 10 / \mathrm{C} 11$ from cFos, c-Jun, and JunD heterodimers to predominantly JunB/ JunD heterodimers. Western blot analysis revealed that while the levels of c-Fos increase slightly, c-Jun and JunD expression remains unchanged following differentiation (Fig. 5). Therefore, levels of c-Fos and c-Jun cannot account for the underrepresentation of c-Fos and c-Jun within the AP-1 complexes in differentiated $9 \mathrm{E}$ cells. The highly elevated level of JunB in differentiated $9 \mathrm{E}$ cells could have resulted in the change in dimerization partners.

(vi) $\mathrm{C12}$ and C13/C14. TRANSFAC analysis did not predict any putative binding site in region $\mathrm{C} 12$. When EMSA was performed, using undifferentiated and differentiated 9E nuclear extracts and $\mathrm{C} 12$ as the probe, no observable DNAprotein complexes were formed (data not shown). TRANSFAC analysis predicted a putative Oct-1 binding site in the $\mathrm{C} 13$ region and a GATA- 1 binding site overlapping regions $\mathrm{C} 13$ and $\mathrm{C} 14$. Gel shift analysis with an undifferentiated nuclear extract and $\mathrm{C} 13 / \mathrm{C} 14$ probe indicated the formation of the complex uC13/C14 I, which was competed by a 100-fold excess of unlabeled $\mathrm{C} 13 / \mathrm{C} 14$ and Oct-1 consensus oligonucleotides, but not a GATA consensus oligonucleotide (Fig. 9). This suggests that region $\mathrm{C} 13 / \mathrm{C} 14$ binds to Oct- 1 in undifferentiated $9 \mathrm{E}$ nuclear extracts. However, EMSA using a differentiated $9 \mathrm{E}$ nuclear extract revealed the formation of a complex, $\mathrm{dC} 13 / \mathrm{C} 14$ I, that was abolished by the addition of unlabeled homologous competitor, but not by GATA or Oct-1 (Fig. 9). Western blot analysis revealed a slight decrease in the Oct-1 level in 9E cells upon differentiation (Fig. 5). The lack of binding by $\mathrm{C} 13 / \mathrm{C} 14$ to Oct-1 in differentiated 9E cells could be attributed either to this decrease in Oct-1 level or to competition with another Oct-1-like factor for binding to the same site.

\section{DISCUSSION}

The transcriptional activity of the HPV E6/E7 promoter is modulated by cis elements contained in the viral URR. Several

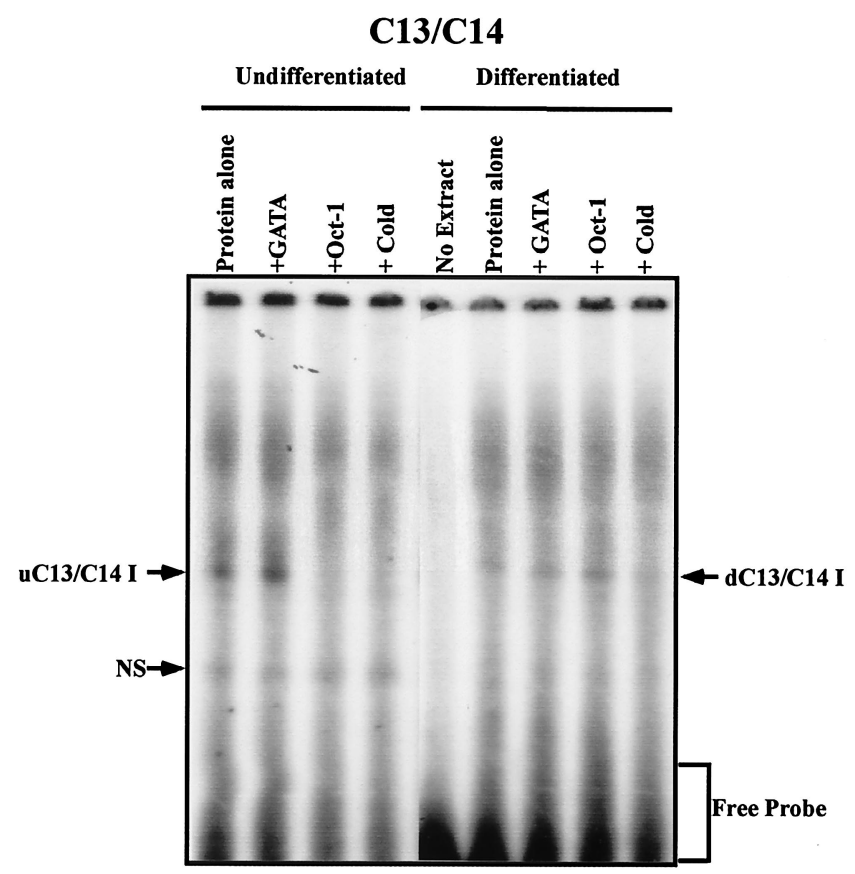

FIG. 9. Characterization of cellular factors that binds to the $\mathrm{C} 13$ / $\mathrm{C} 14$ region by EMSAs. The $\mathrm{C} 13 / \mathrm{C} 14$ probe was incubated with undifferentiated and differentiated 9E nuclear extracts in the presence or absence of a 100-fold excess of competitors, as indicated. Specific DNA protein complexes and nonspecific (NS) complexes are indicated.

cellular factors, including AP-1 family members, AP-2, C/EBP, CDP, GRE, KRF-1, NF1, Oct-1, Sp1, Sp3, TEF-1, and YY1, have been proposed to bind to the URR of various HPV types and to participate in the transcriptional regulation of E6/E7 $(8-10,26,27,32,33,42,50,68,77)$. Modulation of promoter activity by these factors depends on the cell type $(9,18,32)$, the state of differentiation $(1,21,52)$, and viral feedback loops (67). However, many questions regarding the cellular control mechanisms involved in the regulation of E6/E7 promoter activity by cis elements during different stages of the viral life cycle are still unanswered. It is known that the activity of an individual regulatory element can strongly depend on the overall composition of a transcriptional control region, such as potentially cooperating cis motifs, but what role is played by individual cis elements in the cooperative generation of transcriptional regulatory activity exerted by the entire viral URR? Does the transcriptional regulatory activity of each individual cis element become altered with the differentiation-dependent life cycle of the virus? How do host cellular transcription factors and viral factors modulate potential cis regulatory circuits during different stages of the viral life cycle in trans? We have sought answers to these questions by generating linker scanning mutants across the URR. Using this strategy, we have previously identified cis regulatory elements contained within a portion of the 5' URR domain and the AE region of the HPV31 URR that are involved in the regulation of p99 promoter activity at different stages of the viral life cycle (62). In HPV31, the KE is regarded as the major transcriptional activator of viral gene expression (40). Therefore, for the present 
study we extended our linker scanning mutational analysis to the KE (nt 7511 to 7762 ) region.

Undifferentiated keratinocyte culture, which mimics the basal cell environment seen by the virus immediately following infection, was used to analyze the transcriptional regulation of p99 promoter during the initial state of the viral life cycle. A 70 to $90 \%$ decrease in promoter activity was observed when these cell lines were transfected with mutants $\mathrm{C} 7, \mathrm{C} 8, \mathrm{C} 10, \mathrm{C} 13$, and C14. These observations suggest that the cis elements contained within the region are strongly involved in the positive regulation of HPV31 p99 activity, irrespective of cell type. While transfection of $9 \mathrm{E}$ and C33A cells with mutant $\mathrm{C} 9$ had no effect on p99 promoter activity, a $70 \%$ decrease in activity was observed in NHEK upon transfection with this mutant. This indicates that the region replaced by mutant $\mathrm{C} 9$ acts as a positive regulator of transcription only in NHEK. A 50\% increase in promoter activity was observed upon infection of C33A cells with mutant C5, whereas transfection of 9E cells and NHEK with this mutant had no effect on p99 promoter activity. On the other hand, a 60 to $70 \%$ decrease in promoter activity was observed in $\mathrm{C} 33 \mathrm{~A}$ and $9 \mathrm{E}$ cells upon transfection with mutant $\mathrm{C} 11$, while the decrease was less severe in NHEK.

The HPV life cycle is closely associated with the differentiation program of its host tissue, the squamous epithelium. Transfection of 9E cells with mutants $\mathrm{C} 1$ to $\mathrm{C} 3$ and mutants $\mathrm{C} 6$ to $\mathrm{C} 14$ repressed p99 activity by 70 to $95 \%$ compared to the wild-type construct, indicating that the cis elements that are affected by these mutants are involved in positive transcriptional regulation in differentiating $9 \mathrm{E}$ cells. The difference in promoter activity observed between undifferentiated and differentiated 9E cells upon transfection with mutant C9 suggests that the cis element replaced by this mutant is regulated by host tissue differentiation. A general trend towards a significant reduction in promoter activity was observed for most of the mutants in differentiating NHEK. Though no marked difference in promoter activity was observed between the differentiated and undifferentiated systems when NHEK were transfected with mutants $\mathrm{C} 2, \mathrm{C} 3, \mathrm{C} 4$, and C6 through C14, transfection with mutant $\mathrm{C} 5$ resulted in an increase in promoter activity to the level of the wild type upon differentiation.

Depending on the state of differentiation of the host cell, some cellular factors can act as either inducers or repressors of E6/E7 promoter activity $(1,5,49,52)$. TRANSFAC analysis has shown that the KE region of the URR contains numerous abutting and overlapping putative binding sites for several cellular transcription factors. We investigated the interplay between transcription factors and the cis regulatory elements in the $\mathrm{KE}$ region under cellular conditions that represent different stages of the viral life cycle. Regions C1 (nt 7511 to 7528) and $\mathrm{C} 2$ (nt 7529 to 7546 ) did not bind any of the transcription factors predicted by the TRANSFAC search. While the TRANSFAC search predicted C/EBP and NF-1 sites in the $\mathrm{C} 3 / \mathrm{C} 4$ region, it was intriguing to observe that $\mathrm{C} / \mathrm{EBP} \beta$ binds to this region only in undifferentiated $9 \mathrm{E}$ cells, while NF-1-like factor binds to $\mathrm{C} 3 / \mathrm{C} 4$ (nt 7547 to 7582 ) only upon differentiation. This altered DNA-protein interaction could be attributed either to the presence of other unidentified factors, including the NF-1-like factor, that could have prevented $\mathrm{C} / \mathrm{EBP} \beta$ from binding to the $\mathrm{C} 3 / \mathrm{C} 4$ region or to the altered levels of different $\mathrm{C} / \mathrm{EBP} \beta$ isoforms that dictated binding of
$\mathrm{C} / \mathrm{EBP} \beta$ to the $\mathrm{C} 3 / \mathrm{C} 4$ region under undifferentiated cellular conditions. Previous gel mobility shift assays performed with the $\mathrm{C} 3 / \mathrm{C} 4$ region (designated FPI) and using HeLa nuclear extracts suggested that NF-1 itself does not bind to this region and that a novel NF-1-like factor that is distinct from NF-1 binds to this region (40). In HPV16, the enhancer activity is dependent on the presence of specific subsets of NF-1 proteins that differ both in their expression and heterodimerization pattern in different cell types (4).

Though we did not detect any specific binding of cellular factors to regions C5/C6 (nt 7583 to 7618) and C7 (nt 7619 to 7636), previous gel shift assays using this site (designated FPII) and HeLa extracts demonstrated shifted bands that diminished only in the presence of homologous competitor (40). Our transfection studies demonstrated that C5/C6 has no effect on the transcriptional regulation of E6/E7, whereas C7 acts as a strong positive regulator of $\mathrm{p} 99$ activity in both undifferentiated and differentiated $9 \mathrm{E}$ cells, although we were not able to detect binding to these regions by the cellular factors tested. It is possible that the activity of these cis regulatory elements strongly depends on the overall composition of a transcriptional control region, such as potentially cooperating cis motifs or tertiary structures.

Gel mobility shift assays demonstrated that $\mathrm{C} / \mathrm{EBP} \beta$ and the c-Fos/JunD heterodimer bind to the C8/C9 (nt 7637 to 7672) region in undifferentiated $9 \mathrm{E}$ cells. Kyo et al. showed that AP-1 binds to this area (nt 7640 to 7656) and that the enhancer activity of the HPV $31 \mathrm{~b}$ KE region is strongly dependent on a synergistic interaction of AP-1 with NF-1-like and KRF-1-like novel factors (40). Previous studies have shown that $\mathrm{C} / \mathrm{EBP} \beta$ binds to the HPV16 LCR (nt 7454 to 7766) and functions as a negative regulator of early gene expression by competing with AP-1 and NF-1 (38). Since C/EBP $\beta$ is known to complex with Jun and Fos (29), it remains unclear whether C/EBP $\beta$ binds to the $\mathrm{C} 8 / \mathrm{C} 9$ region as a homodimer or a heterodimer with AP-1.

All of the known AP-1 factors are expressed in the epidermis and each is expressed in a specific spatial pattern that suggests its potential to regulate multiple genes (73). Moreover, in the epidermis the selectivity of genes regulated by AP-1 is determined by distinct AP-1 complexes and by interactions with other transcriptional regulators and/or distal regulatory elements. Therefore, simultaneous expression of multiple members of the AP-1 family provides numerous opportunities for complex regulation. AP-1 is regarded as the major determinant of HPV31b enhancer specificity (40), and E6/E7 expression in differentiating epithelia is regulated by AP-1 (39). The dimerization pattern of the AP-1 complex that binds to $\mathrm{C} 8 / \mathrm{C} 9$ changes from c-Fos/JunD heterodimers in undifferentiated $9 \mathrm{E}$ cells to JunB/JunD heterodimers in differentiated 9E cells. By monitoring the corresponding protein expression level, we found the JunB level to be elevated significantly following differentiation. Previous studies on the expression of AP-1 in differentiating epithelia suggested that JunB expression is restricted to differentiating cells (74). Numerous reports have suggested essential and opposite roles for Jun proteins in cell cycle progression, with JunB and JunD monomers having a negative antiproliferative role while c-Jun is the positive counterpart $(6,44,63)$. Although the level of c-Fos is also upregulated following differentiation, the increase in c-Fos expression does not occur to the same extent as that for JunB. Since 
complex formation is a very dynamic process of association and dissociation events, it is tempting to speculate that simple competition with JunB may account for the exclusion of c-Fos from the AP-1 complex. It is known that subtle changes in the concentration of one AP-1 monomeric component can cause a potential widespread effect by titrating out certain monomers and shifting the equilibrium within the AP-1 pool. Even slight changes in the levels of one monomeric component could yield significant qualitative and quantitative shifts in many or even all members of the active multimer pool (7).

A significant decrease in E6/E7 promoter activity was observed when $9 \mathrm{E}$ cells transfected with mutant $\mathrm{C} 9$ were allowed to differentiate. Suppression of E6/E7 expression as a consequence of antioxidant-induced alteration in the heterodimerization pattern of the AP-1 complex has been documented previously (57). Alteration in the heterodimerization pattern of AP-1 and its selective accessibility to opened chromatin structures were shown to represent a novel pathway in the regulation of chemokines in malignant and nonmalignant HPV-positive cells (23). It is possible that a differentiationinduced increase in the level of JunB expression followed by a subsequent alteration in the AP-1 heterodimer component that binds the $\mathrm{C} 8 / \mathrm{C} 9$ region might be sufficient to interfere with the architecture of an HPV-specific transcription complex, resulting in altered E6/E7 expression. In addition to AP-1, $\mathrm{C} / \mathrm{EBP} \beta$ also forms a part of the complex that binds $\mathrm{C} 8 / \mathrm{C}$, and the expression levels of $\mathrm{C} / \mathrm{EBP}$ isoforms were altered following differentiation (Fig. 6). Previous studies also showed that small changes in the ratio of different $\mathrm{C} / \mathrm{EBP} \beta$ isoforms can result in large differences in transcriptional regulation by $\mathrm{C} / \mathrm{EBP} \beta$ (20). HPV16 LCR activity is regulated differentially by different $\mathrm{C} / \mathrm{EBP} \beta$ isoforms (66), and changes in $\mathrm{C} / \mathrm{EBP}$ family members during keratinocyte differentiation are postulated to relieve the negative regulatory effect of $\mathrm{C} / \mathrm{EBP} \beta$ on the HPV11 LCR (71). Moreover, the binding of a C/EBP $\beta-Y Y 1$ protein complex to the switch region is known to be critical for the cell type specificity of the HPV18 URR (10). Therefore, the changing combinations of trans-acting factors binding to the same cis element under different growth conditions may tightly modulate E6/E7 promoter activity.

The C10/C11 region (nt 7673 to 7708) binds AP-1 and Oct-1 in undifferentiated $9 \mathrm{E}$ cells, a finding similar to that observed by Kyo et al. (40). The exact role of Oct- 1 in regulating HPV expression remains controversial $(27,47)$. Interestingly, Oct-1 sites are usually located adjacent to the sites for other transcription factors for HPV, such as TEF-1 (32) and KRF-1 (42). Oct- 1 bound to the $\mathrm{C} 10 / \mathrm{C} 11$ region could function as a transcriptional modulator of HPV by interacting with AP-1 and other additional factors, as was previously suggested (40). EMSA using antibodies against specific members of the AP-1 family showed that C10/C11 bound c-Fos, c-Jun, and JunD, but not JunB, in nuclear extracts from undifferentiated 9E cells. Our results are in agreement with studies that demonstrate that the $\mathrm{C} 10 / 11$ region binds $\mathrm{c}-\mathrm{Fos} / \mathrm{JunD}$ heterodimers and that JunB is not a predominant member of the AP-1 complex (40). However, Thierry et al. have shown that, in undifferentiated human keratinocytes and cervical carcinoma cells, JunB is the predominant Jun family member that interacts with the HPV18 enhancer (68). Variations in the constituents of the
AP-1 complex that bind to the HPV31 minimal enhancer have been observed in different cell types (40).

Competition EMSA revealed that the $\mathrm{C} 10 / \mathrm{C} 11$ region (nt 7673 to 7707 ) binds AP-1, GATA, and Oct-1 in differentiated 9E nuclear extracts. Jun and Fos proteins can associate with members of the GATA family (GATA-1, -2, and -3) of transcription factors through direct protein-protein interaction (36), and a combination of an AP-1 and a GATA site has been shown to provide strong promoter activity (70). Recently, HPV-mediated immortalization has been shown to be associated with down regulation of the transcription factor GATA-3 (64). Whether the cooperativity arising out of the physical association between GATA and AP-1 regulates the transcriptional regulatory potential of the $\mathrm{C} 10 / \mathrm{C} 11$ region in differentiated 9E cells is unclear. In HPV16, Oct-1 does not activate transcription directly but contributes to enhancer activity by tethering NF-1 to the composite element (48). Moreover, Oct1-mediated repression of HPV18 enhancer activity occurs independently of Oct-1 binding to DNA and possibly involves protein-protein interaction (27). Since the presence of Oct-1 antibody had no significant effect on the formation of complexes that bind to the $\mathrm{C} 10 / \mathrm{C} 11$ region in differentiated $9 \mathrm{E}$ cells, it is possible that Oct-1 functions as a modulator by tethering transcriptional regulators AP-1 and GATA to this region without directly interacting with the DNA under differentiated conditions.

The composition of the AP- 1 complex that binds to $\mathrm{C} 10 / \mathrm{C} 11$ changes from c-Fos, c-Jun, and JunD homo- and heterodimers in undifferentiated $9 \mathrm{E}$ cells to JunB and JunD homo- and heterodimers in differentiated $9 \mathrm{E}$ cells. This could have resulted from the elevated level of expression of JunB under differentiated conditions. It is known that the abundance and phosphorylation of Jun proteins vary during the cell cycle (6), and the relative binding affinities of distinct Jun-Fos dimer combinations depend on the expression level and phosphorylation status of individual bZIP proteins, which can differ dramatically depending on cell type and cell context (7). In our study, JunB was observed to be the predominant AP-1 component that binds to both $\mathrm{C} 8 / \mathrm{C} 9$ and $\mathrm{C} 10 / \mathrm{C} 11$ following differentiation. Since expression of JunB and JunD are tightly regulated during cellular differentiation, the defined reorganization of AP-1 may represent a novel mechanism controlling the transcription of pathogenic HPVs during keratinocyte differentiation and in the progression to cervical cancer. In differentiating 9E cells, E6/E7 expression detected by in situ hybridization correlated with the pattern of AP-1 expression detected by immunohistochemical analyses (39). Thus, differences between the AP-1 family members present under different cellular conditions may contribute not only to different binding patterns, but also to the expression levels of E6/E7. Moreover, the interaction of AP-1 with other bZIP family transcription factors could affect or alter AP-1 function under different growth states (58). A variety of DNA structures can be induced at the AP-1 site through combinatorial interactions between different bZIP family proteins. This diversity of DNA structures may contribute to regulatory specificity among the many proteins that can bind to the AP-1 sites (37).

Transcriptional enhancers are not constituted solely of the linear alignment of multiple factors on the DNA. Transcriptional activation requires the establishment of functional inter- 
faces from multiple protein-DNA and protein-protein interactions of regulatory factors. E6/E7 transcription in HPV18 depends upon the assembly of an enhanceosome containing a JunB/Fra-2 heterodimer and the architectural protein HMG$\mathrm{I}(\mathrm{Y})$ recruited by the core enhancer sequence (14). The formation of the enhanceosome is dependent on AP-1 binding, and a nonconsensus Oct-1 binding site has been predicted to bind HMG-I(Y) (14). Thus, the possibility of the recruitment of an enhanceosome-like nucleoprotein complex in the $\mathrm{KE}$ region (containing both AP-1 and the Oct-1 site) cannot be ruled out. Different transcription factors would then interact with the new interfaces created by the higher order nucleoprotein complex formed under different cellular conditions rather than with a specific DNA sequence.

In 9E cells, the region spanning nt 7738 to 7763 has been shown to play an important role in regulating enhancer activity, as mutation of this site decreases promoter activity by $80 \%$ (40). The activity of this site was suggested to be dependent on the binding of a novel KRF-1-like factor (40). Our results indicate the importance of this site in the regulation of enhancer activity, as transfection with mutants $\mathrm{C} 13$ (nt 7727 to 7744) and C14 (nt 7745 to 7762) results in a significant decrease in p99 activity under both undifferentiated and differentiated conditions. However, our gel shift assays suggest that this region binds to Oct-1 in undifferentiated but not in differentiated 9E nuclear extracts.

We interpret these data to mean that even though p99 is a constitutive promoter, it is under differentiation-dependent control, in that cellular proteins involved in its transcriptional control change upon host cell differentiation to maintain the same level of promoter activity. The differential occupancy of the same cis regulatory element by alternative transcription factors under different cellular conditions has been illustrated in Fig. 1B. Different proteins or modified proteins may complex with the same cis element in undifferentiated and differentiated 9E cells, resulting in different patterns of binding and transcriptional control at different stages of the viral life cycle. The activity of any cis regulatory region may be the result of a synergism of factors that occurs in different quantities under different cellular conditions. Differences in the relative concentration of a particular transcription factor, its interaction with other transcription factors, or both in the undifferentiated and differentiated cellular environment could cause the difference in promoter activity observed in 9E cells upon transfection with the mutants. The results obtained in this study help to define the relative contribution of individual cis regulatory elements in the KE region towards the transcriptional regulation of the p99 promoter and to characterize host cell factors that interact with individual cis regulatory regions at different stages of the viral life cycle. The combinatorial effects arising from the variable recruitment of transcription factors to the same cis element under different stages of the viral life cycle may play a crucial role in maintaining a tight link between keratinocyte differentiation, E6/E7 expression, and progression to malignancy.

\section{ACKNOWLEDGMENTS}

We thank David Spector and Mike Fried for many valuable suggestions and Brian Wigdahl for providing the Oct-1 antibody. We thank
Michael Nonnemacher and the Meyers laboratory for helpful discussions.

This work was supported by National Cancer Institute grant RO1 CA 79006 (C.M.).

\section{REFERENCES}

1. Ai, W., E. Toussaint, and A. Roman. 1999. CCAAT displacement protein binds to and negatively regulates human papillomavirus type 6 E6, E7, and E1 promoters. J. Virol. 73:4220-4229.

2. Andersen, B., A. Hariri, M. R. Pittelkow, and M. G. Rosenfeld. 1997. Characterization of Skn-1a/i POU domain factors and linkage to papillomavirus gene expression. J. Biol. Chem. 272:15905-15913.

3. Angel, P., and M. Karin. 1991. The role of Jun, Fos and the AP-1 complex in cell-proliferation and transformation. Biochim. Biophys. Acta 1072:129157

4. Apt, D., T. Chong, Y. Liu, and H. U. Bernard. 1993. Nuclear factor I and epithelial cell-specific transcription of human papillomavirus type 16. J. Virol. 67:4455-4463.

5. Apt, D., R. M. Watts, G. Suske, and H. U. Bernard. 1996. High Sp1/Sp3 ratios in epithelial cells during epithelial differentiation and cellular transformation correlate with the activation of the HPV-16 promoter. Virology 224:281-291.

6. Bakiri, L., D. Lallemand, E. Bossy-Wetzel, and M. Yaniv. 2000. Cell cycledependent variations in c-Jun and JunB phosphorylation: a role in the control of cyclin D1 expression. EMBO J. 19:2056-2068.

7. Bakiri, L., K. Matsuo, M. Wisniewska, E. F. Wagner, and M. Yaniv. 2002. Promoter specificity and biological activity of tethered AP-1 dimers. Mol. Cell. Biol. 22:4952-4964.

8. Bauknecht, T., P. Angel, H. D. Royer, and H. zur Hausen. 1992. Identification of a negative regulatory domain in the human papillomavirus type 18 promoter: interaction with the transcriptional repressor YY1. EMBO J. 11:4607-4617.

9. Bauknecht, T., F. Jundt, I. Herr, T. Oehler, H. Delius, Y. Shi, P. Angel, and H. Zur Hausen. 1995. A switch region determines the cell type-specific positive or negative action of YY1 on the activity of the human papillomavirus type 18 promoter. J. Virol. 69:1-12.

10. Bauknecht, T., R. H. See, and Y. Shi. 1996. A novel C/EBP beta-YY1 complex controls the cell-type-specific activity of the human papillomavirus type 18 upstream regulatory region. J. Virol. 70:7695-7705.

11. Bedell, M. A., J. B. Hudson, T. R. Golub, M. E. Turyk, M. Hosken, G. D. Wilbanks, and L. A. Laimins. 1991. Amplification of human papillomavirus genomes in vitro is dependent on epithelial differentiation. J. Virol. 65:22542260 .

12. Bernard, B. A., C. Bailly, M. C. Lenoir, M. Darmon, F. Thierry, and M. Yaniv. 1989. The human papillomavirus type 18 (HPV18) E2 gene product is a repressor of the HPV18 regulatory region in human keratinocytes. J. Virol. 63:4317-4324.

13. Boshart, M., L. Gissmann, H. Ikenberg, A. Kleinheinz, W. Scheurlen, and H. zur Hausen. 1984. A new type of papillomavirus DNA, its presence in genital cancer biopsies and in cell lines derived from cervical cancer. EMBO J. 3:1151-1157.

14. Bouallaga, I., S. Massicard, M. Yaniv, and F. Thierry. 2000. An enhanceosome containing the Jun B/Fra-2 heterodimer and the HMG-I(Y) architectural protein controls HPV 18 transcription. EMBO Rep. 1:422-427.

15. Bromberg-White, J. L., and C. Meyers. 2002. The upstream regulatory region of human papillomavirus type 31 is insensitive to glucocorticoid induction. J. Virol. 76:9702-9715.

16. Chin, M. T., R. Hirochika, H. Hirochika, T. R. Broker, and L. T. Chow. 1988. Regulation of human papillomavirus type 11 enhancer and E6 promoter by activating and repressing proteins from the E2 open reading frame: functional and biochemical studies. J. Virol. 62:2994-3002.

17. Chinenov, Y., and T. K. Kerppola. 2001. Close encounters of many kinds: Fos-Jun interactions that mediate transcription regulatory specificity. Oncogene 20:2438-2452.

18. Chong, T., D. Apt, B. Gloss, M. Isa, and H. U. Bernard. 1991. The enhancer of human papillomavirus type 16: binding sites for the ubiquitous transcription factors Oct-1, NFA, TEF-2, NF1, and AP-1 participate in epithelial cell-specific transcription. J. Virol. 65:5933-5943.

19. Cripe, T. P., T. H. Haugen, J. P. Turk, F. Tabatabai, P. G. Schmid, M. Durst, L. Gissmann, A. Roman, and L. P. Turek. 1987. Transcriptional regulation of the human papillomavirus-16 E6-E7 promoter by a keratinocyte-dependent enhancer, and by viral E2 trans-activator and repressor gene products: implications for cervical carcinogenesis. EMBO J. 6:3745-3753.

20. Descombes, P., and U. Schibler. 1991. A liver-enriched transcriptional activator protein, LAP, and a transcriptional inhibitory protein, LIP, are translated from the same mRNA. Cell 67:569-579.

21. Dollard, S. C., T. R. Broker, and L. T. Chow. 1993. Regulation of the human papillomavirus type 11 E6 promoter by viral and host transcription factors in primary human keratinocytes. J. Virol. 67:1721-1726.

22. Durst, M., L. Gissmann, H. Ikenberg, and H. zur Hausen. 1983. A papillomavirus DNA from a cervical carcinoma and its prevalence in cancer biopsy 
samples from different geographic regions. Proc. Natl. Acad. Sci. USA 80: 3812-3815.

23. Finzer, P., U. Soto, H. Delius, A. Patzelt, J. F. Coy, A. Poustka, H. zur Hausen, and F. Rosl. 2000. Differential transcriptional regulation of the monocyte-chemoattractant protein-1 (MCP-1) gene in tumorigenic and nontumorigenic HPV 18 positive cells: the role of the chromatin structure and AP-1 composition. Oncogene 19:3235-3244.

24. Flores, E. R., and P. F. Lambert. 1997. Evidence for a switch in the mode of human papillomavirus type 16 DNA replication during the viral life cycle. J. Virol. 71:7167-7179.

25. Heck, D. V., C. L. Yee, P. M. Howley, and K. Munger. 1992. Efficiency of binding the retinoblastoma protein correlates with the transforming capacity of the E7 oncoproteins of the human papillomaviruses. Proc. Natl. Acad. Sci. USA 89:4442-4446.

26. Hoppe-Seyler, F., and K. Butz. 1992. Activation of human papillomavirus type 18 E6-E7 oncogene expression by transcription factor Sp1. Nucleic Acids Res. 20:6701-6706.

27. Hoppe-Seyler, F., K. Butz, and H. zur Hausen. 1991. Repression of the human papillomavirus type 18 enhancer by the cellular transcription factor Oct-1. J. Virol. 65:5613-5618.

28. Howley, P. M. 1996. Papillomavirinae: the viruses and their replication, p 947-978. In D. M. Knipe, B. N. Fields, and P. M. Howley (ed.), Fundamental virology. Lippincott-Raven, Philadelphia, $\mathrm{Pa}$

29. Hsu, W., T. K. Kerppola, P. L. Chen, T. Curran, and S. Chen-Kiang. 1994 Fos and Jun repress transcription activation by NF-IL-6 through association at the basic zipper region. Mol. Cell. Biol. 14:268-276.

30. Hubert, W. G., T. Kanaya, and L. A. Laimins. 1999. DNA replication of human papillomavirus type 31 is modulated by elements of the upstream regulatory region that lie $5^{\prime}$ of the minimal origin. J. Virol. 73:1835-1845.

31. Hummel, M., J. B. Hudson, and L. A. Laimins. 1992. Differentiation-induced and constitutive transcription of human papillomavirus type $31 \mathrm{~b}$ in cell lines containing viral episomes. J. Virol. 66:6070-6080.

32. Ishiji, T., M. J. Lace, S. Parkkinen, R. D. Anderson, T. H. Haugen, T. P. Cripe, J. H. Xiao, I. Davidson, P. Chambon, and L. P. Turek. 1992. Transcriptional enhancer factor (TEF)-1 and its cell-specific coactivator activate human papillomavirus-16 E6 and E7 oncogene transcription in keratinocytes and cervical carcinoma cells. EMBO J. 11:2271-2281.

33. Jundt, F., I. Herr, P. Angel, H. Zur Hausen, and T. Bauknecht. 1995. Transcriptional control of human papillomavirus type 18 oncogene expression in different cell lines: role of transcription factor YY1. Virus Genes 11:53-58.

34. Kanaya, T., S. Kyo, and L. A. Laimins. 1997. The $5^{\prime}$ region of the human papillomavirus type 31 upstream regulatory region acts as an enhancer which augments viral early expression through the action of YY1. Virology 237: 159-169.

35. Karin, M., Z. Liu, and E. Zandi. 1997. AP-1 function and regulation. Curr Opin. Cell Biol. 9:240-246.

36. Kawana, M., M. E. Lee, E. E. Quertermous, and T. Quertermous. 1995 Cooperative interaction of GATA-2 and AP1 regulates transcription of the endothelin-1 gene. Mol. Cell. Biol. 15:4225-4231.

37. Kerppola, T. K., and T. Curran. 1993. Selective DNA bending by a variety of bZIP proteins. Mol. Cell. Biol. 13:5479-5489.

38. Kyo, S., M. Inoue, Y. Nishio, K. Nakanishi, S. Akira, H. Inoue, M. Yutsudo, O. Tanizawa, and A. Hakura. 1993. NF-IL-6 represses early gene expression of human papillomavirus type 16 through binding to the noncoding region. J. Virol. 67:1058-1066

39. Kyo, S., D. J. Klumpp, M. Inoue, T. Kanaya, and L. A. Laimins. 1997 Expression of AP1 during cellular differentiation determines human papillomavirus E6/E7 expression in stratified epithelial cells. J. Gen. Virol. 78: 401-411.

40. Kyo, S., A. Tam, and L. A. Laimins. 1995. Transcriptional activity of human papillomavirus type $31 \mathrm{~b}$ enhancer is regulated through synergistic interaction of AP1 with two novel cellular factors. Virology 211:184-197.

41. Latchman, D. S. 1991. Eukaryotic transcription factors. Academic Press, London, United Kingdom.

42. Mack, D. H., and L. A. Laimins. 1991. A keratinocyte-specific transcription factor, KRF-1, interacts with AP-1 to activate expression of human papillomavirus type 18 in squamous epithelial cells. Proc. Natl. Acad. Sci. USA 88:9102-9106.

43. Maytin, E. V., and J. F. Habener. 1998. Transcription factors C/EBP alpha, C/EBP beta, and CHOP (Gadd153) expressed during the differentiation program of keratinocytes in vitro and in vivo. J. Investig. Dermatol. 110:238246.

44. Mechta-Grigoriou, F., D. Gerald, and M. Yaniv. 2001. The mammalian Jun proteins: redundancy and specificity. Oncogene 20:2378-2389.

45. Meyers, C., S. Alam, M. Mane, and P. L. Hermonat. 2001. Altered biology of adeno-associated virus type 2 and human papillomavirus during dual infection of natural host tissue. Virology 287:30-39.

46. Meyers, C., M. G. Frattini, J. B. Hudson, and L. A. Laimins. 1992. Biosynthesis of human papillomavirus from a continuous cell line upon epithelial differentiation. Science 257:971-973.

47. Morris, P. J., C. L. Dent, C. J. Ring, and D. S. Latchman. 1993. The octamer binding site in the HPV16 regulatory region produces opposite effects on gene expression in cervical and non-cervical cells. Nucleic Acids Res. 21: $1019-1023$.

48. O'Connor, M., and H. U. Bernard. 1995. Oct-1 activates the epithelialspecific enhancer of human papillomavirus type 16 via a synergistic interaction with NFI at a conserved composite regulatory element. Virology 207: $77-88$.

49. O'Connor, M. J., W. Stunkel, C. H. Koh, H. Zimmermann, and H. U. Bernard. 2000. The differentiation-specific factor CDP/Cut represses transcription and replication of human papillomaviruses through a conserved silencing element. J. Virol. 74:401-410.

50. Offord, E. A., and P. Beard. 1990. A member of the activator protein 1 family found in keratinocytes but not in fibroblasts required for transcription from a human papillomavirus type 18 promoter. J. Virol. 64:4792-4798.

51. Ozbun, M. A., and C. Meyers. 1998. Temporal usage of multiple promoters during the life cycle of human papillomavirus type 31b. J. Virol. 72:27152722.

52. Parker, J. N., W. Zhao, K. J. Askins, T. R. Broker, and L. T. Chow. 1997. Mutational analyses of differentiation-dependent human papillomavirus type 18 enhancer elements in epithelial raft cultures of neonatal foreskin keratinocytes. Cell Growth Differ. 8:751-762.

53. Pattison, S., D. G. Skalnik, and A. Roman. 1997. CCAAT displacement protein, a regulator of differentiation-specific gene expression, binds a negative regulatory element within the $5^{\prime}$ end of the human papillomavirus type 6 long control region. J. Virol. 71:2013-2022.

54. Pfister, H. 1987. Relationship of papillomaviruses to anogenital cancer. Obstet. Gynecol. Clin. N. Am. 14:349-361.

55. Romanczuk, H., F. Thierry, and P. M. Howley. 1990. Mutational analysis of cis elements involved in E2 modulation of human papillomavirus type 16 P97 and type 18 P105 promoters. J. Virol. 64:2849-2859.

56. Ron, D., and J. F. Habener. 1992. CHOP, a novel developmentally regulated nuclear protein that dimerizes with transcription factors C/EBP and LAP and functions as a dominant-negative inhibitor of gene transcription. Genes Dev. 6:439-453.

57. Rosl, F., B. C. Das, M. Lengert, K. Geletneky, and H. zur Hausen. 1997. Antioxidant-induced changes of the AP-1 transcription complex are paralleled by a selective suppression of human papillomavirus transcription. J. Virol. 71:362-370.

58. Rossi, A., S. I. Jang, R. Ceci, P. M. Steinert, and N. G. Markova. 1998. Effect of AP1 transcription factors on the regulation of transcription in normal human epidermal keratinocytes. J. Investig. Dermatol. 110:34-40.

59. Ruesch, M. N., F. Stubenrauch, and L. A. Laimins. 1998. Activation of papillomavirus late gene transcription and genome amplification upon differentiation in semisolid medium is coincident with expression of involucrin and transglutaminase but not keratin-10. J. Virol. 72:5016-5024.

60. Scheffner, M., B. A. Werness, J. M. Huibregtse, A. J. Levine, and P. M. Howley. 1990. The E6 oncoprotein encoded by human papillomavirus types 16 and 18 promotes the degradation of p53. Cell 63:1129-1136.

61. Schreiber, E., P. Matthias, M. M. Muller, and W. Schaffner. 1989. Rapid detection of octamer binding proteins with "mini-extracts," prepared from a small number of cells. Nucleic Acids Res. 17:6419.

62. Sen, E., J. L. Bromberg-White, and C. Meyers. 2002. Genetic analysis of cis regulatory elements within the $5^{\prime}$ region of the human papillomavirus type 31 upstream regulatory region during different stages of the viral life cycle. J. Virol. 76:4798-4809.

63. Shaulian, E., and M. Karin. 2002. AP-1 as a regulator of cell life and death. Nat. Cell Biol. 4:E131-E136.

64. Steenbergen, R. D., V. E. OudeEngberink, D. Kramer, H. F. Schrijnemakers, R. H. Verheijen, C. J. Meijer, and P. J. Snijders. 2002. Down-regulation of GATA-3 expression during human papillomavirus-mediated immortalization and cervical carcinogenesis. Am. J. Pathol. 160:1945-1951.

65. Stern, S., M. Tanaka, and W. Herr. 1989. The Oct-1 homeodomain directs formation of a multiprotein-DNA complex with the HSV transactivator VP16. Nature 341:624-630.

66. Struyk, L., E. van der Meijden, R. Minnaar, V. Fontaine, I. Meijer, and J. Ter Schegget. 2000. Transcriptional regulation of human papillomavirus type 16 LCR by different C/EBPbeta isoforms. Mol. Carcinog. 28:42-50.

67. Tan, S. H., B. Gloss, and H. U. Bernard. 1992. During negative regulation of the human papillomavirus-16 E6 promoter, the viral E2 protein can displace Sp1 from a proximal promoter element. Nucleic Acids Res. 20:251-256.

68. Thierry, F., G. Spyrou, M. Yaniv, and P. Howley. 1992. Two AP1 sites binding JunB are essential for human papillomavirus type 18 transcription in keratinocytes. J. Virol. 66:3740-3748.

69. Vinson, C., M. Myakishev, A. Acharya, A. A. Mir, J. R. Moll, and M. Bonovich. 2002. Classification of human B-ZIP proteins based on dimerization properties. Mol. Cell. Biol. 22:6321-6335.

70. Walters, M., and D. I. Martin. 1992. Functional erythroid promoters created by interaction of the transcription factor GATA-1 with CACCC and AP-1/ NFE-2 elements. Proc. Natl. Acad. Sci. USA 89:10444-10448.

71. Wang, H., K. Liu, F. Yuan, L. Berdichevsky, L. B. Taichman, and K. Auborn. 1996. C/EBPbeta is a negative regulator of human papillomavirus type 11 in keratinocytes. J. Virol. 70:4839-4844. 
72. Wedel, A., and H. W. Ziegler-Heitbrock. 1995. The C/EBP family of transcription factors. Immunobiology 193:171-185.

73. Welter, J. F., and R. L. Eckert. 1995. Differential expression of the fos and jun family members c-fos, fosB, Fra-1, Fra-2, c-jun, junB and junD during human epidermal keratinocyte differentiation. Oncogene 11:26812687.

74. Wilkinson, D. G., S. Bhatt, R. P. Ryseck, and R. Bravo. 1989. Tissue-specific expression of c-jun and junB during organogenesis in the mouse. Development 106:465-471.
75. Wingender, E., X. Chen, R. Hehl, H. Karas, I. Liebich, V. Matys, T. Meinhardt, M. Pruss, I. Reuter, and F. Schacherer. 2000. TRANSFAC: an integrated system for gene expression regulation. Nucleic Acids Res. 28:316-319.

76. Yukawa, K., K. Butz, T. Yasui, H. Kikutani, and F. Hoppe-Seyler. 1996 Regulation of human papillomavirus transcription by the differentiationdependent epithelial factor Epoc-1/skn-1a. J. Virol. 70:10-16.

77. Zhao, W., L. T. Chow, and T. R. Broker. 1997. Transcription activities of human papillomavirus type 11 E6 promoter-proximal elements in raft and submerged cultures of foreskin keratinocytes. J. Virol. 71:8832-8840. 